\title{
Türk Stratejik Kültüründe Çözümü Çerçevelemek: Katmanlı Bir Harekât Tasarımı Önerisi
}

Framing the Solution in Turkish Strategic Culture:

$\ddot{o}_{z}$

Harpte kullanilan araç ve yöntemlerin değişmesi hususunda esas belirleyici olan şey "maksattır”. Maksat, stratejik seviyede siyasi/askerî elitin, operatif seviyede ise komutanın zihninde oluşan, muhasamatın sonucuna dair bir görüdür. Mevcut durumun ve istenen son durumun anlaşılması ise harekât tasarımı olarak adlandırılan bir sürecin sonucunda ortaya çıkar. Stratejik ve operatif seviyede harekâta ilişkin meseleler, karmaşık, bulanık ve kötü yapılandırılmışlardır. Günümüz hibrit harekât ortamında, lineer bir bakış açısına bağımlı kalmamak gerektiği ve tasarımın pragmatik yaklaşımla çok katmanlı bir hale getirilmesinin karar alıcılara bilişsel bir esneklik să̆layabileceği

\footnotetext{
* Dr.Öğr.Üyesi, Millî Savunma Üniversitesi Kara Harp Enstitüsü Askerî Strateji Çalışmaları Ana Bilim Dalı Başkanlığı, ORCID: 0000-0002-7633-7596, e-posta: okorpe@msu.edu.tr.

Geliş Tarihi / Submitted: 04.02.2021

Kabul Tarihi / Accepted: 09.03.2021

1 "Amacı tam olarak belirlemeden muharebe yapılmaz. Muharebe sırasında da amacı göZ önünden asla uzak tutmamak gerekir.” Mustafa Kemal Atatürk, Taktik Meselesinin Çözümüne ve Emirlerin Yazılmasına İlişkin Öğütler, Genelkurmay Basımevi, Ankara, 2011, s. 12.
} 


\section{Özgür KÖRPE}

158

Güvenlik Stratejileri

Cilt: 17

Sayı: 37

değerlendirilmektedir. Pragmatik katmanl yaklaşım stratejik kültür yazarlarinca da benimsenir ve Türk stratejik kültüründe de problem çözmede pragmatik yaklaşımın izlerine siklıkla rastlanır. Bu makalede, harekât tasarımı, katmanl yaklaşımla, bir tür bulanık mantık çerçevesinde yeniden ele alındi. Harekât tasarımının geliştirilmesi için kullanılan diğer yöntemler ortaya koyuldu ve yaygın olarak uygulanan ağırlık merkezi temelli zihin haritalaması yaklaşımının eksiklikleri gösterildi. Bunun yerine yeni bir harekât tasarımı yöntemi önerildi.

Anahtar Kelimeler: Uluslararası Güvenlik, Niteliksel Yöntemler, Harekât Tasarımı, Türk Stratejik Kültürü, Pragmatizm.

\section{Abstract}

The main determinant in terms of changing the means and methods used in war is the "purpose". The aim is a vision of the outcome of the hostility, formed in the mind of the political / military elite at the strategic level and the commander at the operative level. The understanding of the current situation and the desired final state emerges as a result of a process called operational design. Operational issues at the strategic and operative level are complex, blurred and poorly structured. In today's complex operational environment, it is considered that one should not be dependent on a linear perspective and that multi-layered design can provide cognitive flexibility to decision-makers. Pragmatic layered approach is also adopted by strategic culture writers and traces of pragmatic approach to problem solving are frequently encountered in Turkish strategic culture. In this article, the operational design is reconsidered with a layered approach, in a kind of fuzzy logic. Other methods used to improve the operational design were introduced and the shortcomings of the widely applied center of gravity-based mind mapping approach were demonstrated. Instead, a new method of operation design was proposed.

Keywords: International Security, Qualitative Methods, Operational Design, Turkish Strategic Culture, Pragmatism. 
Türk Stratejik Kültüründe Çözümü Çerçevelemek:

Katmanlı Bir Harekât Tasarımı Önerisi

\section{Giriş}

Harpler ve harekât ${ }^{2}$ ortamı karmaşık hale geldikçe, harp ve harekâtın öngörülmesi, tasarlanması, planlanması ve icrasına ilişkin yeni kavramlar da gelişmektedir. Öte yandan harbe ilişkin kavramsallaştırma periyotları gittikçe sıklaşmakta, kuramlar arasındaki aralık daralmaktadır. $\mathrm{Bu}$ nedenle diğer sosyal bilimlerde olduğu gibi uluslararası güvenlik ve strateji araștırmaları alanında da karmaşıklıkla ilişkili kuramlar yaygın hale gelmiş, bazıları akademik derinliğe sahip olmasalar da bu alana yönelik yayınlar artmıştır.

Her şeyden önce harp, doğası gereği riskler ve belirsizliklerle doludur. Subay ve komutanın başlıca görevi ise bu riskleri yönetmek ve belirsizliği azaltmaktır. Akademisyenlerin harplerin ne zaman çok boyutlu ve çok aktörlü hale geldiğine ilişkin milat belirleme, harbi nesillere ayırma ve kategorize etme gayretlerine ilişkin ortak özellik, bu gayretlerin hiçbirisinin yeni olmamasıdır.

Teknolojik, toplumsal ya da siyasi gelişmelerin tüm etkileri bir yana bırakılırsa, harpte kullanılan araç ve yöntemlerin değișmesi hususunda esas belirleyici olan şey "maksattır". ${ }^{3}$ Maksat, stratejik seviyede $^{4}$ siyasi/askerî karar alıcıların, operatif/taktik seviyede ise

\footnotetext{
2 "Harp", silahlı bir mücadele, "harekât" ise bu mücadeleyi kazanmaya yönelik icra edilen askerî faaliyetlerdir. Metinde akıcılığı sağlamak maksadıyla, kimi zaman "harp" yerine "savaş" kavramı da kullanılmıştır.

3 "Maksat", "gaye", "hedef" ve "amaç" kavramlarının arasındaki anlam ayrımına dikkat etmek gerekir. Literatürde "amaç" kelimesinin, diğer üç kelimeyi kapsayacak şekilde kullanılması, "mana birleșmesi problemi”" olarak eleștirilmektedir. Ayrıntılı bilgi için Bknz. Yasin Yayla, "Türkiye Türkçesinde mana birleșmesi problemi: "Gaye", "Hedef", "Maksat", "Amaç" örneği”, Rumelide Dil ve Edebiyat Araștırmaları Dergisi, 2020, Sayı:20, 145-156. Diğer taraftan "amaç" Türkiye Türkçesinde yaygınlașmıș durumdadır. Biz bunun farkında olarak, "amaç" kelimesini, diğer kelimelerin anlam farklılıklarının bilincinde olarak kullanmaya gayret ediyoruz.

${ }^{4}$ Askerî literatürde sıkça kullanılan ve günümüzde genel akademik ve aktüel literatürde de yaygın bir kullanım alanı bulan harbin seviyeleri, millî menfaatleri destekleyen askerî gücü harp alanı ve muharebelere tatbik etmek için bir yapı sağlar. Harbin üç seviyesi olarak, stratejik, operatif ve taktik seviye kavramları kullanılmaktadır. Bunların askerî faaliyetler olarak düşünülmesi de mümkündür. Stratejik seviye millî menfaatlerin korunması ve millî
}

\section{9}

Güvenlik Stratejileri

Cilt: 17

Say1: 37 


\section{Özgür KÖRPE}

160

Güvenlik Stratejileri

Cilt: 17

Sayı: 37

komutanın zihninde oluşan, muhasamatın sonucuna dair bir görüdür. Stratejik seviyede maksat, karar alıcının "gayesi" veya "ülküsü" olarak ifade edilir. Harbe ve bu bağlamda harekâta ilişkin tüm planlama gayreti de işte bu maksada ulaşmaya yöneliktir. Ancak maksadı belirlemenin ön şartı, meseleyi ve onun çözümünü anlamak; diğer bir deyişle çözümü çerçevelemektir.

Clausewitz'in de belirttiği gibi; ${ }^{5}$ devlet adamı ve komutanın ilk vereceği, en önemli ve kesin sonucu en çok etkileyici hüküm; giriştiği harbi bu ilişkiler içinde iyi tanımak, onu olduğundan başka türlü değerlendirmemek ya da hal ve şartların müsaade edemeyeceği bir şekle sokmaya çalışmamaktır. Bu, stratejik soruların ilki ve en kapsamlısıdır. Clausewitz'in stratejik seviyeye yönelik bu vurgusu, harekât tasarımını aynı zamanda uluslararası güvenlik alanına bağlamaktadır. Çünkü esasen çerçevelenmesi gereken problem [bundan sonra mesele olarak ifade edilecek], uluslararası sistemin yap1s1 nedeniyle [ister NeoRealist, ister Yapısalcı, ister Post-Yapısalcı açıdan bakılsın] karmaşık hale gelmektedir.

Karmaşıklık hayatın her alanında, bu çalışmanın özelinde askerî harekâtın her seviyesinde karşılaşılabilen bir olguysa da karmaşıklığ azaltabilecek imkân ve kabiliyetlere ancak operatif ve stratejik seviyede ulaşılabilir. Diğer bir deyişle taktik seviyedeki bir karar alıcının elinde, karmaşıklı̆ı azaltmak için, operatif ve stratejik seviyedeki karar alıcılardan daha az kaynak vardır. $\mathrm{Bu}$ nedenle taktik seviyedeki komutanlar operatif seviyenin kararlarını hayata geçirirler, uygulamaya dönüştürürler. Ancak bu durum operatif seviyeye; taktik seviyenin işini iyi bir plan yapmak suretiyle kolaylaştırmak sorumluluğunu da yükler.

Bilindiği üzere askerî planlamalar, Askerî Karar Verme Süreci (AKVES) adı verilen bir sürece tâbidir. AKVES, farklı detaylara sahip

hedeflerin elde edilmesiyle ilgili en üst seviyeyi; operatif seviye, büyük birliklerin sevk ve idaresini ve harbin sanat yönünü; taktik seviye, birliklerin muharebe sahasindaki taktik durumun gereklerine göre düzenlenmesini ve manevra yapmalarını ifade eder.

${ }^{5}$ Carl von Clausewitz, Savaş Üzerine, (Çev. H. Fahri Çeliker), Özne Yayınları, İstanbul, 1999, s. 36. 
Türk Stratejik Kültüründe Çözümü Çerçevelemek:

Katmanlı Bir Harekât Tasarımı Önerisi

olmakla birlikte, her seviyede uygulanır. Örneğin taktik seviye için fiziki hedefler ile manevrayı belirlemek; bunu icra edecek kuvveti hazırlamak önem kazanırken, stratejik/operatif seviye için istenen son durumu, harekâtın maksadını, muhasım ağırlık merkezlerini ve bunlarla ilişkili harekât yaklaşımlarını belirlemek önceliklidir.

Maksadı, yöntem ve yaklaşımları belirlemek ise harbin hesaplamasına özgü belirsizlik ve karmaşıklıkla da birleşen çetrefilli bir görevdir. Çatışmaya neden olan karmaşık sorunlar, özünde kötüdür. Dahası, harbin meydana geldiği uluslararası sistem, harbi bir yöntem olarak seçen devletler, harbi yürüten silahlı kuvvetler ve nihayet harbin kendisi de karmaşık uyabilen sistemlerdir. ${ }^{6}$ Harp, bileşenleri ve bağlamları doğrusal olmayan, karmaşık, çoğu zaman iteratif, öte yandan insani ve öngörülemez bir olgudur.

Yine de stratejik/operatif karar alıcının, iyi bir gelecek tasarlama ve ona doğru düzenli bir yol inşa etme sorumluluğu harbin karmaşık doğası nedeniyle ortadan kalkmaz. Nitekim Sun Tzu, Jomini, Clausewitz gibi düşünürler de harbin planlanmasındaki titiz analitik süreçlerin değerine vurgu yapmışlardır. Atatürk de Taktik Meselesinin Çözümüne İlişkin Öğ̈̈tler adlı eserinde meselenin çözümünde kullanılacak en iyi yöntemin, düşünceleri şu birkaç kısa soru etrafinda toplamak olduğunu söyler: ${ }^{7}$

\footnotetext{
${ }^{6}$ Bahsedilen yapılar düzenli ve karmaşıktırlar; çünkü yapısal özelliklerini ortaya koymak oldukça zordur. Düzenlilikleri, bir sosyal düzen ya da ekosistem içinde yer almalarından, karmaşıklıkları ise bu düzen içinde karmaşıklık ve belirsizlik alanı yaratmalarından kaynaklanır. Bir ortam içinde kendi başına hareket edebilen bu tarz sistemler "özerk etken" olarak adlandırılır. Bağımsız varlığa sahip bütün hücreler ve organizasyonlar özerk etkenlerdir. Bir özerk etken; kendisini çoğaltma yani üreme ve en az bir iş döngüsünü yerine getirme gücüne; kısacası "uyabilme" niteliğine sahiptir. Karmaşı uyabilen sistemler, yani Complex Adaptive Systems, "etken" denen çok sayıda etkileşimli bileşenden oluşur; bu bileşenler etkileşime girerken birbirlerine ayak uydurur ya da birbirlerinden öğrenirler. Ayrıntılı bilgi için Bknz. John Brockman, Gelecek 50 Yıl: 21. Yüzyılın İlk Yarısında Sanat ve Bilim, (Çev. Nurettin Elhüseyni), NTV Yayınları, İstanbul, 2008.

${ }^{7}$ Atatürk, Taktik Meselesinin Çözümüne ve Emirlerin Yazılmasına İlişkin Öğ̈̈tler, s. 6.
}

\section{1}

Güvenlik Stratejileri

Cilt: 17

Say1: 37 
162

Güvenlik Stratejileri

Cilt: 17

Sayı: 37

1. Görev ve durumun gerektirdiği önlemler nelerdir? 2. Düşman bu tedbirleri almamızı nasıl önleyebilir? 3. Düşmanı kendi isteğimize göre harekete zorlayabilmek ve onun amacina ulaşmasına engel olabilmek için neler yapabiliriz? Bu soruya cevap vermek için, tarafların kuvveti, bu kuvvetlerin tertiplenmesi, arazi, her iki tarafın ulaşım hatları göz önüne alınarak olası durumlar ortaya çıkarılmalıdır. 4. Alınacak ilk önlemler için karar!

Özetle Atatürk, meselenin çözümüne durumun anlaşılması ve vazifenin tahliliyle başlamayı önerir. İşe düşmanın muhtemel maksatlarından başlamayı ise, komutanın kararını düşmanın maksatlarına bağlı kılabileceği için önermez. Esasen Atatürk'ün bu yaklaşımı, örtük şekilde de olsa, Türk stratejik kültüründe yerleşik olan eylemsel fayda odaklı karar verme eğilimlerini işaret ediyor. Gerçekten de Atatürk'ün bizzat kaleme aldığ1 eserlerde sıklıkla "maksat ve gaye", "hatt-1 harekât" ve "niyet" gibi kavramları kullanması bir tesadüf değildir.

Atatürk'ün vurgulamalarından da görüleceği üzere vazife tahlili ile mevcut durum ve istenen son durum arasında kuvvetli bir ilişki vardır. Zira vazife tahlili mevcut durumdan yola çıkarak, komutanın karşı karşıya olduğu meseleyi anlama ve mesele çözüldügünde istenen son durumun ne olacağını belirleme işlemidir. İstenen son durum operatif ve taktik seviyede vazifenin maksadiyla ifade edilir. Komutan, "ben bu harekâtı icra ettiğimde oluşmasını beklediğim askerî ve politik şartlar nelerdir?" sorusunun cevabını bulduğunda, vazifesinin maksadını da tespit etmiş olur. Diğer bir deyişle operatif/taktik seviyedeki komutanın vazifesinin maksadı, onun icra edeceği harekâtın sonunda neye ulaşmayı beklediğini ifade eder. Benzer bir bilişsel süreç stratejik karar alıcının zihninde de bu kez istenen son durumun belirlenmesi için gerçekleşir. Mevcut durumun ve istenen son durumun anlaşılması ise birçok hesaplamanın sonucunda ortaya çıkar. Bu hesaplama gerçekliği aynı zamanda harekât tasarımının da özüdür. Göz ardı edilmemesi gereken, hesaplamanın, karmaşıklığa yönelik olarak; maksatlı, faydacı, safhalı, esnek, işe yarar, ezcümle pragmatik bir çözümü vadetmesi zorunluluğudur. 
Türk Stratejik Kültüründe Çözümü Çerçevelemek:

Katmanlı Bir Harekât Tasarımı Önerisi

Bu makale stratejik kültür ile harekât tasarımı ve askerî karar verme arasındaki ilişkiyi tespit etmekte, harekât tasarımını kavramsal olarak ele alıp AKVES'teki yerini netleştirmekte ve pragmatik bir bilişsel arka planı olan harekât tasarımının stratejik kültürden bağımsız olmadığını vurgulamakta, bu bağlamda tasarımda kullanılan zihin haritalama yönteminin çok katmanlı hale getirilmesini önermektedir.

\section{AKVES'i Doğru Anlamak, Stratejik Kültürü Doğru Kullanmak}

Günümüzde AKVES'i eskimiş ve kullanışsız gösteren yüzeysel değerlendirmeler yapılmaktadır. Ancak AKVES'i bilinçli ya da bilinçsiz olarak küçümseyenler, subayın muharebedeki rolüne saldırmış olurlar. Zira adıyla müsemma "subay", birinci görevi karar vermek olan askerdir. Kaldı ki bir mesele tanımlama ve çözme yöntemi olan AKVES'i küçümsemek mantıken de hatalıdır. Herhangi bir mesele tanımlama ve çözme metodunu eleştirenlerin ise eskisinden daha verimli bir öneri sunmaları beklenir. Aksi takdirde bu eleştiri "mesele vardır ama onu anlamayalım ve çözmeyelim" demek olur. Bilimsel temeli olmayan küçümseyici eleştiriler ise "boş sözler" olmaktan öteye gidemez. Diğer taraftan, temel mantığını göz ardı etmemek kaydıyla, AKVES metodolojisinin belli bölümleri pek tabii ki eleştirilebilir.

Yakın zamanda rastladığımız bazı yayınlarda, AKVES'in günümüz harekât ortamına uygulanamayacak kadar eskidiği ileri sürülmüștür. Halbuki AKVES bilişsel ve iteratif bir süreçtir, meselenin anlaşılması ve çözülmesi olarak iki ana safhadan oluşur. Önerilen metotlar bu nedenle AKVES'in iteratif mantığını sıklıkla 1skalarlar. Önerilmesi gereken, AKVES'i terk etmek değil, hibrit ${ }^{8}$ meselelerin anlaşılması ve çözümü için AKVES'in iteratif mantığına, yaratıcılığı ilave etmektir.

\footnotetext{
${ }^{8}$ Günümüzün karmaşık toplumunda ya da Kardeş'in Schmitt'ten aktarımıyla "plastik çağda", savaşın değişen doğasına ilişkin farklı tanımlamalar da bulunmaktadır. Örn. Kardeş, günümüz savaşlarının yıkıcı ve hukuk kurmayan birer "yönsüzleşmiş savaşlar" olduklarını vurgular (M. Ertan Kardeş, Yönsüzleşmiş Savaşlar, Pinhan Yayıncılık, İstanbul, 2019, s. 13-14). Kavramın daha anlaşılır olabilmesi maksadıyla, bu makalede,
}

163

Güvenlik Stratejileri

Cilt: 17

Say1: 37 
164

Güvenlik Stratejileri

Cilt: 17

Sayı: 37

Yine bazı yayınlarda AKVES, karar almayı kalıplara sınırlayan bir sorun olarak gösterilmiştir. Halbuki AKVES bir kalıp değildir; meseleyi çözmede ihtiyaç duyulabilecek asgari unsurları öneren mantıki bir sıradır. AKVES'i kalıp olarak kabul eden ise yüzeysel bakıș açısıdır. Yönetim ve organizasyon kuramcıları dahi AKVES'ten esinlenmişlerdir. Atatürk'ün eserlerinden, çağdaş yabancı doktrinlere kadar pek çok yayında benzer metodoloji görülebilir. Kısacası AKVES'in bilimselliğinde ve etkinliğinde bir sorun yoktur. Sorun, AKVES' in karar alıcılara yeteri kadar anlatılamamış olması, AKVES içeriklerinin çağdaş gerekliliklere göre güncellenmemesi ve karar alırken AKVES şablonunun asgari maddelerine, durumun gerektirdiği yaratıcı birtakım süreçler eklemekten kaçınılmasıdır. Ayrıca ilerideki bölümlerde ortaya koyulacağı üzere, meseleyi çözmek öncelikle taktik seviyenin görevidir. Operatif seviyenin öncelikli görevi ise ortam1, meseleyi ve çözümü doğru bir şekilde çerçevelemektir.

Son dönemdeki yayınlarda stratejik kültür kavramının da tam olarak anlaşılmadığı ve AKVES'le bağlantısının kurulamadığı görülmektedir. Örneğin bu metinlerde; stratejik kültür kavramının asıl üreticisi olan Snyder yerine başka yazarlar adres gösterilmekte, stratejik kültüre karar alıcının kültürlenmesinden başka bir değer yüklenememekte, bu nedenle kavram olduğundan çok daha geniş kullanılmakta ve Booth'un "kültür taassubu" uyarısı dikkate alınmamaktadır. Halbuki Snyder, "Stratejik Kültür Kavramı: Sorumluluk Kullanıcınındır" adlı makalesinde, orijinal stratejik kültür kavramının bu kadar geniş bir anlamının olmadığını ve o zamandan bu yana kendisine ait bu kavramın genellikle politik kültür veya millî kültür ile birleştirildiğini işaret etmiştir. Snyder, stratejik kültür de dâhil olmak üzere, kültürün; sadece diğer her şey başarısız olduğunda kullanılması

bu kavramlar arasında en popüler ve askerî doktrine yerleşmekte olan "hibrit" kelimesi tercih edilmiştir. Diğer taraftan bu makalenin yazarı, Hegel'in "alacakaranlıkta uçar Minerva'nın baykuşu" vecizesine atfen, devam etmekte olan bir fenomen hakkında erken hüküm vermekten uzak durmaktadır. Savaștaki dönüșümün bir siyasi bir sınır meselesi olduğu ve yönsüzleştiği hususunda Kardeş’le aynı fikirdedir. 
Türk Stratejik Kültüründe Çözümü Çerçevelemek:

Katmanlı Bir Harekât Tasarımı Önerisi

gereken bir açıklama olduğunu ısrarla vurgulamıştır ki bu husus daha önce başka bir makalede ortaya koyulmuştu. ${ }^{9}$ Benzer şekilde Ken Booth'un stratejik kültürü, bir ulusun stratejik ortama uyabilmede ve mesele çözmede kullandığı yöntem olarak özetlediği de aynı makalede söylenmişti. Nitekim Snyder "(fikirlerime) kalıcı değerini gösteren bir katkı, Ken Booth'un kültür taassubundan dolayı stratejik düşüncede doğabilecek olan tehlikelere dikkat çekmesi olmuştur" sözleriyle, stratejik kültürün bir nevi yöntemsel sinırlılığını vurgular. ${ }^{10}$

Kaldı ki son dönem araştırmalarında, Gray-Johnston tartışmasından da bihaber olarak, karar verme süreçlerine stratejik kültürü esas alan tarihsel ve/veya daraltılmış yanlışlanabilir bir yöntem önerisi de getirilememektedir. Herhangi bir kavram, surf moda olduğu için aceleyle stratejik kültüre bağlanmakta, stratejik kültür yorumlaması "bu kavram bizim kültürümüzde var" gibi, deneysel olarak sınanamayan, yüzeysel olumluma ifadelerinden ibaret kalmaktadır. Halbuki üçüncü nesil stratejik kültür yazarları, bu alandaki analizlerin yanlışlanabilir bir kurama ulaşmayı amaç edinmelerini vurgularlar. Örneğin Johnston, daraltılmış tanımlama için; bilişsel haritalama ve inançsal operasyonel kodları içeren sembol çözümlemesi yöntemlerini önerir. ${ }^{11}$

Stratejik kültür analizine soyunan bazı yayınlarda da kurum kültürü kavramı, Jones'un ortaya koyduğu stratejik kültür analiz düzeylerinden habersiz bir şekilde en üst analiz birimi olarak tanımlanmaktadır. Öte yandan yayınların stratejik kültürün katman ve ince ayar niteliğinden de habersiz olmaları; AKVES'in iteratif ve pragmatik niteliğini görememe sebeplerindendir. Kısacası AKVES sadece holistik değildir; aynı zamanda pragmatik, iteratif, entegre ve heüristiktir.

\footnotetext{
${ }^{9}$ Özgür Körpe, "Stratejik Kültür ve Güncel Kuramsal Tartışmalar", Güvenlik Stratejileri Dergisi, Kasım 2016, Y11: 12, Say1: 24, 147-182, s. 162.

${ }^{10}$ Jack L. Snyder, "The Concept of Strategic Culture: Caveat Emptor," in C.G. Jacobsen, (ed.), Strategic Power: USA/USSR, St Martin's Press, New York, NY, USA, 1990, 3-9, p. 3.

${ }^{11}$ Alastair I. Johnston, Cultural Realism: Strategic Culture and Grand Strategy in Chinese History, Princeton University Press, Princeton, USA: 1998, pp. 42-43.
}

\section{5}

Güvenlik Stratejileri

Cilt: 17

Say1: 37 
Özgür KÖRPE

166

Güvenlik Stratejileri

Cilt: 17

Sayı: 37

\section{Harekât Tasarımında Karmaşııklıktan Hibritliğe:} Kökenler, Tanımlar, Süreçler

Son iki asırda meydana gelen değişimler, harekât ortamını kaçınılmaz bir şekilde ve tarihin hiçbir devrinde olmadığ 1 kadar karmaşık hale getirmiştir. Karmaşıklık ise özünde belirme, buluş, öğrenme ve uyabilmenin doğasıyla ilgilidir. Waldrop'a göre, karmaşık olan sorunlar ancak bütüncül bir yaklaşımla ve eşzamanlı olarak çözülebilir. Bunun için, karmaşık sosyal sistemleri önce düzen içinde konumlandırmak gerekir. ${ }^{12}$ İşte stratejik ve operatif seviyedeki karar alıcı, karşılaştığ 1 karmaşık ve kötü meseleleri tanımlamak için, sistem teorisinin operatif sanata uygulanması anlamına gelen harekât tasarımını kullanır.

Harekât tasarımı, karar alıcının stratejik/operatif seviyede karşılaştığ modellemeden yararlanmasıdır. İlk kullanıcısı olan Goffman'a göre çerçeve; bireyin olayları anlamlandırdığı yorum şemasıdır. ${ }^{13}$ Goffman'ın meseleyi anlamanın karşılığı olarak ortaya attığı çerçeveleme kavramı, karar verme alanında benimsenmiş ve yaygınlaşmıştır. ABD doktrini de harekât tasarımını; "karmaşık, kötü yapılanmış meseleleri anlamak, görselleştirmek, tanımlamak ve bunları çözecek yaklaşımlar geliştirmek için eleştirel ve yaratıcı düşünceyi uygulamaya yönelik bir metodoloji" ${ }^{14}$ olarak tanımlar. Schmitt'e göre bir harekât meselesi, "kötü" bir sorundur. Pek tabii ki çoğu sorun, değişen derecelerde kötülük sergiler. Stratejik ve operatif meseleler bundan da ötede, aşırı derecede kötü olma eğilimindedirler. Ancak bu "şeytani bir kötülük" anlamına gelmez.

\footnotetext{
${ }^{12}$ Melanie Mitchell Waldrop, Complexity: The Emerging Science at the Edge of Order and Chaos, Simon \& Schuster Paperbacks, New York, NY, USA 1992, p. 14.

${ }^{13}$ Goffman, bu kavramı Bateson, Austin, Schwayder gibi yazarlardan ödünç aldığını da söylemiştir. Erving Goffman, Frame analysis: An essay on the organization of experience, Harvard University Press, Cambridge, MA, USA, 1974, pp. 7-9.

${ }^{14}$ Joint Warfighting Center, Design in Military Operations, JWFC Publication, Norfolk, Virginia, USA 2011, p. 4; FM 5-0, Operations Process, Department of Army, Washington, DC, USA 2010, p. 3-1.
} 
Türk Stratejik Kültüründe Çözümü Çerçevelemek:

Katmanlı Bir Harekât Tasarımı Önerisi

Daha çok meydan okuyucu, kötü yapılandırılmış, bulanık ve karmaşık anlamina gelir.

Gerçekten de stratejik ve operatif meseleler çözülemez değildirler ama zor ve kafa karıştırıcıdırlar. Doğaları gereği, kötü yapılandırılmış meselelerin çözümüne daha az, tanımlanmalarına ise daha fazla gayret sarf edilir. ${ }^{15} \mathrm{Bu}$ gayret sarfinın öncelik sıralamasında da önce tanımlama, sonra çözme vardır. Harekât tasarımı, sistem yaklaşımının ve bununla yakın ilişkisi olan etki odaklı harekâtın $(\mathrm{EOH})$, karar süreçlerine yansıyan bilişsel bir sonucudur. Hatırlanacağı üzere EOH, karmaşık harekât ortamında, askerî güce destek olarak diğer güç unsurlarının da kullanılmasıyla; hasmın kabiliyetlerini ve ihtiyaçlarını belirleyip, ardından onun bu en hassas noktalarına etki ederek onu yenmeyi amaçlar. EOH'ın amaçl1lığ $1{ }^{16}$ onu felsefi olarak pragmatizme bağlarken, bilişsel ve yöntemsel olarak da kritik kabiliyetler/kritik hassasiyetler/kritik ihtiyaçlar yaklaşımını ve ağırlık merkezi analizini doğurmuştur. ABD Müşterek Doktrinine göre ${ }^{17}$ harekât tasarımı planlamadan hemen önce başlar ve planlamayla eşzamanlı olarak süregider.

Kötü meseleler ve stratejik seviyenin bu konudaki yönlendirmesi genellikle geniş ve dinamik olduğundan; harekât tasarımı meselenin tespitine, diğer bir deyişle vazifenin tahlili sonuçlarına odaklanır. Harekât tasarımı mantığı; eğer bir mesele yeterince iyi anlaş11ırsa, meselenin çözümünün de kendiliğinden ortaya çıkacağı önermesine dayanır. ${ }^{18}$ Harekât tasarımının meseleyi doğru belirleme konusuna odaklanmas1, onu AKVES'in vazife tahliliyle birlikte ilk analitik

\footnotetext{
${ }^{15}$ Horst W.J Rittel \& Melvin M. Weber, "Dilemmas in a General Theory of Planning", Policy Sciences, (4), 1973, pp. 160-167, akt. John F. Schmitt, "A Systemic Concept for Operational Design", the Marine Corps Combat Development Command, Concepts and Plans Division, Marine Corps Warfighting Lab, August 2006., p. 9.

${ }^{16}$ Amaçlılık, maksatlı olma halini ifade eder. Büyük Türkçe Sözlük'te (2009) "maksatlı" kelimesi "amaçlı"; "amaçlı" kelimesinin karşılığı da "gayeli" olduğundan, bu araştırmada, telaffuzu daha kolay olan "amaçlılık" kelimesi tercih edilmiştir. Ancak "maksatlılık" kelimesi de aynı anlamı karşılar.

${ }_{17}^{17}$ JWF, Design in Military Operations, p. 32; FM 5-0, Operations Process, p. 3-1.

${ }^{18}$ Schmitt, a.g.e., s. 3, 5 .
}

167

Güvenlik Stratejileri

Cilt: 17

Say1: 37 
168

Güvenlik Stratejileri

Cilt: 17

Sayı: 37

faaliyetlerinden birisi haline getirir. Schmitt'e göre tasarım, meseleyi tanımlama; planlama ise meseleyi çözme faaliyetidir. ${ }^{19}$ Harekât Tasarımı meseleyi çözmek için bir yaklaşım ortaya çıkacak şekilde onun altta yatan nedenlerini, yapısını ve işleyiş dinamiklerini bulmayı, tanımlamayı ve modellemeyi içerir. Planlama ise genellikle yerleşik birtakım prosedürlerinin (örneğin Durum Muhakemesi bunlardan birisidir) işletilmesi yoluyla, uygulanacak bir dizi eylemi tasarlama sürecidir. Taktik seviyede meselenin tanımlanması için tek başına vazife tahlili yeterliyken; operatif ve stratejik seviyede meselenin tanımlanması için; vazife tahliline harekât tasarımının da ilave edilmesi gerekmektedir.

Karmaşılı̆̆ın çözümü için geliştirilen sistem yaklaşımı, Amerika Birleşik Devletleri (ABD) kökenlidir ve 1970’lerden sonra kendisini göstermeye başlamıştır. Sovyetler Birliği harekât doktrini üzerinde yapılan araştırmaların da bir sonucu olarak, 1980'lerde Amerikan askerî söyleminde "harbin operatif seviyesi" adında yeni bir kavram ortaya çıkmıştır. Davison, operatif seviye kavramıyla ilgili kısa bir tarihçe verir:

O ylllara kadar stratejik düzeyde karar vermeyi yönlendirmek için çok şey yazılmıştı. Taktik seviyede problem çözme yaklaşımları ise doğrusaldı ve daha üst komutanlık seviyeleri için yetersiz kalmaktaydı. Stratejik ve taktik arasında gidip gelen ara kademelerdeki karar alıcılar, stratejik seviyenin görülerini ve niyetlerini sahadaki icracı komutanlara ustalıkla aktaracak olan harp sanatını elle tutulur hale getirebilmek için, entelektüel yaklaşımlar aradılar. Üstelik bu yaklaşımlar bilimsel titizliğe ve sanatsal yaratıcılığın esnekliğine sahip olmalıydılar. Böylece 1980'lerden itibaren sistem yaklaşımı ve tasarım yöntemleri, operatif sanattaki boşluğu doldurmak maksadiyla, strateji ve harekât söylemine girmiş oldu. ${ }^{20}$

${ }^{19}$ A.e., s..3, 15 .

${ }^{20}$ Ketti, C. Davison, Systemic Operational Design (SOD): Gaining and Maintaining the Cognitive Initiative, BiblioScholar, Washington DC, USA 2012, pp. 4-11. 
Türk Stratejik Kültüründe Çözümü Çerçevelemek:

Katmanlı Bir Harekât Tasarımı Önerisi

Tasarım ve operatif sanat arasındaki ilişki, bu kavramların ve üreticilerinin harbin operatif seviyesi üzerinde araştırmalar yapan ABD Silahlı Kuvvetleri çevrelerinde taraftar bulmasıyla güçlenmiş ve buradan da müttefik ordulara yayılmıştır. ${ }^{21} \mathrm{Bu}$ yazarlara göre, sistem düşüncesi operatif sanata üç ana katkı sağlamıştır. ${ }^{22}$ İlk olarak kendi kuvvetlerini karmaşık, hiyerarşik bir sistem olarak kavramsallaştırmak, operatif komutanın "sistemi stratejik amacına ulaşmaya yönlendirmekten" ibaret olan rolünü anlamasını sağlamıştır. İkinci katkı, komutanın kendi kuvvetleri ve hasım kuvvetler hakkında yapacağı bir sistem analizinin, her iki tarafın güçlü ve zayıf yönlerinin daha iyi anlaşılmasını sağlaması ya da en azından anlaşılma firsatının yakalanabileceğini göstermesi olmuştur. Son olarak sistem yaklaşımı, operatif öğrenmeyi kolaylaştırmış; kendi gücünü, rakibin zayıf yanları üzerinden tanımlamaya ve eşleştirebilmeye imkân sağlayan "diyalektik düşünmeyi”" geliştirmiştir.

ABD'nin sistem yaklaşımının geliştirmesinde Vietnam Harbi'nin ve Küba Krizi'nin büyük bir etkisinin olduğunu; Afganistan ve Irak Özgürlük Harekâtı'ndan alınan derslerin ardından bu konudaki çalışmaların hızlandığını da not etmek gerekir. ${ }^{23}$ Son yıllarda ABD'de harekât tasarımının çeşitli perspektiflerini savunan yayımlar yapılmaktadır. Jeffrey M. Reilly, Harekât Tasarımı: Karar Eylemi İçin Netliği Karmaşıklıktan Aylklamak adlı eserinde, "harekât tasarımı, ortak doktrinde ortaya çıkan belki de en önemli dönüşümdür" demektedir. ${ }^{24}$ Diğer taraftan ABD'li Emekli Orgeneral James N. Mattis, harekât planlama süreçlerinin "aşırı derecede prosedürleştirilmesine" karşı uyarıda bulunur ve harekât tasarımını, müşterek harekât planlaması içinde "açıklığı, dikkatli düşünmeyi ve yaratıcıllı̆ı" canlandırmanın bir yolu olarak görür. ${ }^{25}$ Ancak her ne kadar Reilly ve Mattis gibi yazarlar

\footnotetext{
${ }^{21}$ A.e., s. 12.

${ }^{22}$ Shimon Naveh, In Pursuit of Military Excellence, Routledge, Cambridge, USA, 1997, p. 7.

23 Jeffrey M. Reilly, Operational Design: Distilling Clarity from Complexity for Decisive Action, Air University Press, Alabama, USA, 2021, p. 67.

${ }^{24}$ A.e., s. 1.

${ }^{25}$ James N. Mattis, "Memorandum for US Joint Forces Command: Vision for a Joint
}

\section{9}

Güvenlik Stratejileri

Cilt: 17

Say1: 37 


\section{Özgür KÖRPE}

170

Güvenlik Stratejileri

Cilt: 17

Sayı: 37

harekât tasarımının önemine vurgu yapmış olsalar da bu konuda ortak bir doktrinin oluşturulması, doğası gereği sinkretik ve zaman alacak bir süreçtir.

Maksadın belirlenmesi ve çözümün modellenmesi meselenin çözümündeki seçkin yerini korumaktadır. Ancak günümüzde tasarımın sadece karmaşıklıkla sınırlanması mümkün değildir. Günümüz harekât meseleleri, hem kesin bir askerî başarı elde etmek hem de bir terörist yapılanmayı sindirmek/etkisiz hale getirmek maksadıyla; sivil işlerin, konvansiyonel ve konvansiyonel olmayan harekâtın bir kombinasyonunu gerektirebilecek şekilde hibrittir. Bu yüzden de karmaşıklık yaklaşımının kötü meseleler argümanını kabul etmekle birlikte, meseleye yaklaşımda karmaşıklık kavramını tek başına yeterli görmüyor ve "hibrit" kavramının göz önüne alınmasını öneriyoruz. En basit biçimiyle hibrit savaş tabiriyle, konvansiyonel ve konvansiyonel olmayan taktiklerin bir arada kullanıldığı harp türü anlaşılır. Kavramı şimdiki manasında ilk kez kullanan Hoffman'a göre hibrit savaş; birçok savaş çeşidinin yaratıcı bir şekilde aynı anda kullanıldığı bir savaş türüdür. ${ }^{26}$ Hibrit harekât ortamı; karmaşık ortamdan farklı ve onu kapsayacak şekilde, lineer ve iteratif olmayan, çok katmanlı ve bulanık bir yapıdır. Muharebe sahasını yurtiçi sahasından ayıran sınırlar belirsiz, asker-sivil ayrımı bulanık, muharip, terörist ve organize suçlu arasındaki hukuki fark ise istismara açıktır. Hibrit meseleler, sofistike, esnek, uyabilen ve pragmatiktirler. ${ }^{27}$

\section{Türk Stratejik Kültüründe Harekât Tasarımının Pragmatik Niteliği}

Hoffman hibrit savaşın pragmatik niteliğini, ünlü İngiliz ajanı Lawrence'a dayandırır ve ona atıfla, gelecek muharebe sahasında bilişsel

Approach to Operational Design.” Norfolk, VA: US Joint Forces Command, 6 October 2009, JFCOM web sitesi, http://www.jfcom.mil/newslink/storyarchive/2009/aod_2009.pdf, p. 43, (Erişim Tarihi 30.01.2021).

${ }^{26}$ Frank G. Hoffman, Conflict in the 21st Century: The Rise of Hybrid Wars, Potomac Institute for Policy Studies, Virginia, USA, 2007, p. 17.

${ }^{27}$ A.e., s. 5, 7, 11, 52. 
Türk Stratejik Kültüründe Çözümü Çerçevelemek:

Katmanlı Bir Harekât Tasarımı Önerisi

alanın tarihin hiçbir döneminde olmadığı kadar önem kazanacağını iddia eder. ${ }^{28}$ Hoffman'ın, teorisini esasen Türklere karşı mücadelesine dayandıran Lawrence'a atıfi, Türk Stratejik Kültürünün harekât tasarımına pragmatik yaklaşımını incelemek hususunda teşvik edicidir. Zira tüm toplumsal olgular gibi, askerî meseleler için de kültür belirgin bir tanımlama biçimidir. Bunun için stratejik kültür kavramı kullanılır. Snyder da stratejik kültürdeki değişimi açıklamada düz eski siyasetin veya pragmatizmin, en yararlı prizmayı sağlayacağını ifade eder $^{29}$.

Goffman, çerçevenin ifade ettiği anlamın örtük kültürel kökenleri olduğunu vurgular. ${ }^{30}$ Goffman'ın bu tespiti de harekât tasarımını stratejik kültürle ilişkilendirmeye imkân sağlar. Zira stratejik kültür (harp tarihçilerinin daha çok benimsediği şekliyle savaş tarzı), karar alma davranışına kültürel kodlar üzerinden açıklamalar getirmeyi esas alır. Stratejik kültür alanında, kavramın üreticileri de dâhil olmak üzere, kapsam ve yöntem tartışmaları vardır. $\mathrm{Bu}$ araştırma, tüm tartışmaların bilincinde olarak; kapsamı dar tutma ve başka bir çözüm ihtimali kalmadığı takdirde stratejik kültüre başvurma (Snyder), kültür taassubundan kaçınma (Booth), tarihsel miras ve kültürlenmeye önem verme (Gray), yanlışlanabilirlik (Johnston), ince ayar (Longhurst) ve katman (Morgan) önerilerine sadık kalmaktadır. Bu bağlamda stratejik kültür kavramını gelişigüzel kullanmadığımızı; stratejik kültür analizini Türk stratejik kültüründeki harekât tasarımını inceleyecek kadar daralttığımızı; Türk stratejik kültürünü bağımsız değişken yaparak, kültürün katman niteliğini, operatif sanatın uygulamasında yanlışlanabilir bir bağımlı değişken olarak ortaya koyduğumuzu vurgulamakta yarar vardır.

Zira katmanlı yaklaşım stratejik kültür kuramcılarının da işaret ettikleri bir yöntemdir. Basrur, stratejik kültürü iç ve dış uyaranlar arasında bir katman olarak nitelendirir. ${ }^{31}$ Morgan bakımından stratejik

\footnotetext{
${ }^{28}$ A.e., s. 52.

${ }^{29}$ Snyder, a.g.e., s. 8.

${ }^{30}$ Goffman, a.g.e., s. 22.

31 Rajesh M. Basrur, "Nuclear Weapons and Indian Strategic Culture," Journal of
}

\section{1}

Güvenlik Stratejileri

Cilt: 17

Say1: 37 


\section{Özgür KÖRPE}

172

Güvenlik Stratejileri

Cilt: 17

Sayı: 37

kültür, stratejik çevreden gelen uyarıcılar ile karar alıcının bu uyaranlara tepkisini (bu makalenin problematiği bakımından meselenin tanımlanması) ilişkilendiren bir aracı değişkendir. ${ }^{32}$ Longhurst de stratejik kültürün ayarlanabilen katman niteliğini pragmatik bir "ince ayar" olarak adlandırır. ${ }^{33}$ Biz bu ince ayarı, tasarıma her seferinde bir katman ekleyerek yapmayı öneriyoruz. $\mathrm{Bu}$ yöntemle karar alıcının çevresel uyarana (meseleye) tepkisinin işlevsel hale getirilebileceğini düşünüyoruz.

Nitekim Cicero'nun da dediği gibi, bu gökyüzünün altında söylenmemiş söz yoktur. Sistem yaklaşımı ve harekât tasarımı kavramsallaştırmasından çok önce de komutanlar meseleyi tanımlamak ve sınırlandırmak hususuna kafa yormuşlardır. Pek çok harp tarihi örneğinde görülebileceği üzere, esasen tüm karar alıcıların ve harekât planlayıcılarının ana sorunsalı "maliyet etkin bir harekât yönetim metodu olabilir mi?" sorusunun cevabını bulabilmektir. Neticede sistem yaklaşımı fikrinin de Birinci Dünya Savaşı sonrası Sovyet harekât doktrininin tarihsel bir analizi neticesinde ortaya çıktığı daha önce vurgulanmıştı. ${ }^{34}$ Dolayısıyla harekât tasarımı unsurlarının çoğu ne askerî teori için yeni ne de harekât planlaması için yenidir. Bu bağlamda Tyler da harekât tasarımını, eleştirel ve sistemsel düşünme, iteratif süreçler, örgütsel öğrenme, yaratıcı liderlik ile ekip oluşturma şeklinde dört ana fikirden müteşekkil kavramsal bir çerçeveye dayandırır. ${ }^{35}$

Esasen bu dört ana fikir, eş anlamlı tanımlamalarla Clausewitz'in Savaş Üzerine adlı eserinde de bulunur. ${ }^{36}$ Fiziksel, zihinsel ve ahlaki

Peace Research, 2001, Vol. 38, 181-198, p. 195.

${ }^{32}$ Forrest E. Morgan, Compellence and the Strategic Culture of Imperial Japan: Implications for Coercive Diplomacy in the Twenty-First Century, Praeger Publishers, Westport, CT, USA, 2003, p. 42.

${ }^{33}$ Kerry Longhurst, Germany and the Use of Force: The Evolution of Germany Security Policy 1990-2003 (Issues in German Politics), Manchester University Press, Mancherster, UK, 2005, p. 26.

${ }^{34}$ Naveh, a.g.e., s. 6.

${ }^{35}$ Brian J. Tyler, Intelligence and Design: Thinking about Operational Art, Air University Press, Alabama, USA, 2014, p. 67.

${ }^{36}$ Clausewitz, a.g.e., s. 37, 70, 76, 566, 567. 
Türk Stratejik Kültüründe Çözümü Çerçevelemek:

Katmanlı Bir Harekât Tasarımı Önerisi

faktörlerin birbirine bağl1lı̆̆ (Die wunderliche Dreifaltigkeit-Acayip Üçleme); ağırlık merkezinin tespitine verilen önem (Das SchwerpunktAğırlık Merkezi) ve öngörülemezlikle ilgili kaygı (Der KriegsnebelSavaş Sisi ve Die Friktion-Sürtünme), onun eleştirel ve sistematik düşünme (önce parçala ve sonra tekrar bütünleştir) yöntemlerindeki ustalığını göstermektedir. Yine, iki taraflı bir görüngü olan savaşın "asla kısa bir darbe ya da nihai bir izole eylem olmadığını" ${ }^{37}$ tekrar tekrar vurgulaması iteratif süreçlere işaret eder ki bu; savaşın dinamik doğasının uyabilmeye ve öğrenmeye istekli bir komutana sunduğu fırsatları da göstermesi bakımından anlamlıdır. Son olarak Clausewitz, deha biçimindeki yaratıcı liderliğin (Das Kriegerische Genie-Savaşçı Dahi), meselenin çerçevelenmesi için olağanüstü bir avantaj sağladığına da inanmıştır. ${ }^{38}$

Harekât tasarımı mantığında işaret edilen sentetik-analitik yaklaşım pragmatik bir bilişsel süreci ifade eder. Bu bağlamda Schmitt'in dörtlü çerçevesine "pragmatik düşünmeyi" ilave etmenin faydalı olabileceğini değerlendiriyoruz. Bu noktada bu iddiayı açıklamakta yarar vardır.

Hatırlanacağı üzere pragmatizm, bir önermenin tatmin edici biçimde işe yaradığı takdirde doğru olduğunu ve söz konusu önermenin, sadece uygulamalı sonuçlarının dikkate alınması gerektiğini savunur. Pragmatizme göre pratik olmayan fikirler reddedilmelidir. Kırık ve Morva, ister pozitivist-analitik, isterse de fenomenoloji olsun, ana akım felsefe açısından eylemin, açıklanmaya muhtaç, şarta bağlı, deneysel bir görüngü olduğunu tespit ederler. ${ }^{39}$ Pragmatizm ise, tüm bu felsefi akımlardan farklı olarak, eylemi bütün açıklamaların başlangıcı olan evrensel bir görüngü olarak taçlandırır.

Kisaca eylemin felsefesi olarak tanımlanabilen ve maksatlı bir eylemciliği karşılayan pragmatizm, daha önce var olan fikir ve

\footnotetext{
${ }^{37}$ A.e., s. 25.

${ }^{38}$ A.e., s. 52.

39 Hikmet Kırık ve Oya Morva, Cumhuriyet ve Pragmatizm: Yazılmamış Kuram, Doruk Yayıncılık, İstanbul 2016, s. 9.
}

\section{3}

Güvenlik Stratejileri

Cilt: 17

Say1: 37 


\section{Özgür KÖRPE}

174

Güvenlik Stratejileri

Cilt: 17

Sayı: 37

uygulamalardan faydalanma önerisini, kendi kendisine de uygular ve felsefesini eylemsel fayda ölçütüne göre yapılandırır. Bundan dolayıdır ki, birçok felsefi akımda pragmatik olarak adlandırılabilecek akıl yürütmelere rastlanabilir. Ya da tam tersine, Pragmatizm felsefenin birçok dalından izler taşır.

Askerî karar verme de harekâtın maksadına uygun, maliyet etkin, safhalı ve işe yarar çözüm vaadeden bir planlama ve icrayı esas alır. Hatta bir adım daha ileri giderek, pragmatizmin savaş gibi kriz hallerinde başvurulan bir yaklaşım olduğunu söylemek de mümkündür. Bu nedenle operatif sanatın (bu makalenin özelinde harekât tasarımının) bilişsel yapısıyla pragmatizmin bağlantısını tespit etmek için özel bir çabaya gerek kalmaz.

Harekât tasarımı ve pragmatizm arasındaki en belirgin bağlantı "maksat" ve "safhalandırma" üzerindendir. Bu konuyla ilgili olarak Axelrod detaylı bir bakış açısı sunuyor. ${ }^{40}$ Axelrod'a göre bir karar alıcı, dış dünyada karşılaştı̆̆ 1 karmaşıklıkları basitleştirmelidir. Bu bağlamda da çevresini tanımlayabilmek ve onunla baş edebilmek için, dış dünyanın yönetilebilir bir temsilini oluşturabilmelidir. Bu temsilin gerekçeli kararlar verebilmek için kullanılması, olası seçimleri potansiyel sonuçlarla ilişkilendiren bazı inançları gerektirmektedir.

Axelrod'a göre seçimi ve sonucu bağlayan bir inancın ana özelliği, genellikle dolaylı olmasıdır; bir kişi genellikle bir seçimden sonuca kadar tekil bir tümdengelim sıçraması yapamaz. ${ }^{41}$ Bunun yerine, bu süreci safhalara ayırarak; "Belirli bir seçim yaparsam ve diğer aktörler de böyle böyle yaparlarsa ve o sırada dış dünyanın özellikleri de böyle böyle olursa, o zaman belli tahmini sonuçlar, spesifik sonuçlara dönüşür"” diye düşünür. $\mathrm{Bu}$ durumda bahse konu spesifik sonuçların; beklenen etkilere sahip olan, bu beklenen etkilerin de kendilerine ait etkileri olan

${ }^{40}$ Robert Axelrod, "Decision for Neoimperialism: The Deliberations of the British Eastern Committee in 1918" in Structure of Decision: Cognitive Maps of Political Elites, Robert Axelrod, (ed.), Princeton University Press, New Jersey, USA, 1976, 77-95.

${ }^{41}$ A.e., s. 77. 
Türk Stratejik Kültüründe Çözümü Çerçevelemek:

Katmanlı Bir Harekât Tasarımı Önerisi

ve böylece devam eden beklenen yansımaları olur. Axelrod'a göre "seçimin bu doğrudan ve dolaylı sonuçları, çıktının beklenen değerini belirlemek olarak kabul edilebilir." ${ }^{2}$ İşte stratejik ve operatif meselelerin tanımlanması ve çözümünde buna "istenen son durum" adı verilir. Pragmatik bilişsel yapının özellikleri, Kırık ve Morva'nın ile Axelrod'un seçim ve sonuç bağlantısından yararlanılarak belirlenmiş ve ilerideki bölümlerde detaylarıyla görüleceği üzere, harekât tasarımının bir katmanı olarak yararlanılmıştır.

Yukarıdaki bilgilendirme 1şı̆̆ında, pragmatik düşünmeyi Schmitt'in dörtlü kavramsal çerçevesine bir simetri merkezi şeklinde ekleyerek, harekât tasarımını beş noktalı hale getirmenin, AKVES'te meselenin tanımlanması sorunsalı bakımından daha açıklayıcı olabileceği değerlendirilmektedir. Bu bağlamda meselenin tanımlanması Şekil 1'de görülen bir çerçeveye kavuşmuş olacaktır.

Şekil 1. Harekât Tasarımının Fikrî Çerçevesi

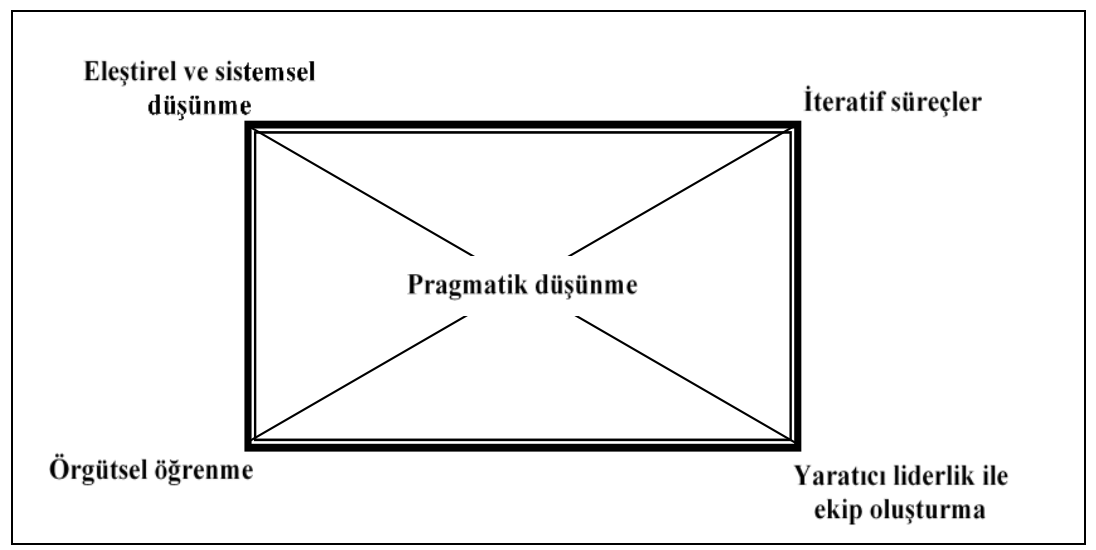

${ }^{42}$ A.e., s. 79. 


\section{Özgür KÖRPE}

176

Güvenlik Stratejileri

Cilt: 17

Sayı: 37

$\mathrm{Bu}$ araştırmada önerilen harekât tasarımının fikrî çerçevesi, Türk Stratejik Kültüründen ilham almaktadır. Pek tabii ki ortaya koyduğumuz ölçütlerden yararlanılarak, pek çok karar alıcıların bilişsel/sembolik analizleri yapılabilir. Ama biz bu makalede, Türk stratejik kültürünün başat karar alıcı figürü olan Atatürk'ün söyleminden elde edilen bulgulara yer vereceğiz. Atatürk'ün "savaş, sürekli mücadele halinde bulunan gözle görülmez kuvvetlerin göze görünür şekil ve görünüş almasıdır" yönetmek önemlidir" "44 sözleri, Schmitt'in ortaya koyduğu eleştirel düşünme biçimine verilebilecek örneklerden bazılarıdır. Keza, "eğer ben askerî yaşamımda, Suriye geri çekilme hareketinin bir kısmını yönetmemiş olsaydım, Sakarya Meydan Savaşı'ndan önce geri çekilme hareketini yapmaya bu kadar kesinlikle cesaret edemezdim" sözü de Atatürk'ün operatif sanatın iteratif süreçleri ve öğrenme konusundaki farkındalığını ortaya koyar. "Komutan olan bir kimsenin, büyük bir kararlılıkla firsatları elden kaçırmaması gerekir. Aynı zamanda, akla uygun olan şeyleri izlemesi gerekir" sözü ise Atatürk'ün yaratıc1 liderliğiyle ilgili verilebilecek pek çok örnekten yalnızca birisidir. Öyleyse Türk Stratejik Kültüründe harekât tasarımının fikrî çerçevesinin simetri merkezi olan pragmatik düşünmenin önemli bir yeri vardır. ${ }^{45}$ Nitekim Atatürk Nutuk'ta, pragmatik düşünce ölçütlerine uygun olarak, uygulamayı safhalara ayırmak ve maksat ve gayeye (amaca) süreç boyunca sadık kalmak hususunda şunları söylemektedir:

“Türk ata yurduna ve Türk'ün istiklâline saldıranlar kimler olursa olsun, onlara bütün milletçe silâhla karşı koymak ve onlarla

\footnotetext{
${ }^{43}$ Atatürk Kültür, Dil ve Tarih Yüksek Kurumu Atatürk Araştırma Merkezi, Atatürk'ün Söylev ve Demeçleri I-III (Açıklamalı Dizin ile), Ankara 2006, s. 206.

${ }^{44}$ Mustafa Kemal Atatürk, Anafartalar Muharebeleri'ne Ait Tarihçe, yay.krl. Abdullah Atay, Sertif Demir, Yusuf Serdar Demirtaş, Genelkurmay Askerî Tarih ve Stratejik Etüt Başkanlığı Yayınları, Ankara 2011, s. 23.

${ }^{45}$ Atatürk'ün Türk Stratejik Kültüründe pragmatik bir ince ayar niteliği teşkil eden karar verme davranışı ile ilgili ayrı bir detaylı araştırmayı işaret ediyor. Ayrıntılı bilgi için bkz. Özgür Körpe, Cesur ve Pragmatik: Atatürk ve Türk Stratejik Kültüründeki İnce Ayar, İlgi Kültür Yayınc1lık, İstanbul, 2021.
} 
Türk Stratejik Kültüründe Çözümü Çerçevelemek:

Katmanlı Bir Harekât Tasarımı Önerisi

çarpışmak gerekiyordu. Bu önemli kararın bütün gerek ve zaruretlerini daha ilk gününde açığa vurup ifade etmek, elbette isabetli olamazdı. Uygulamayı birtakım safhalara ayırmak, olaylardan ve olayların akışından yararlanarak milletin duygu ve düşüncelerini hazırlamak ve basamak basamak ilerleyerek hedefe ulaşmaya çalışmak gerekiyordu. Nitekim öyle olmuştur. Eğer dokuz yıllık faaliyetimiz ve yaptıklarımız bir mantık silsilesi ile gözden geçirilirse, ilk günden bugüne kadar takip ettiğimiz genel doğrultunun, ilk kararın çizdiği yoldan ve yöneldiği hedeften asla sapmamış olduğu kendiliğinden anlaşı1ır." ${ }^{46}$

Pragmatik bilişsel yapının özellikleri ise aynı zamanda pragmatik davranışın ölçütleri olarak, Kırık ve Morva ile Axelrod'un tespitlerinden yola çıkılarak belirlenmiştir (Tablo 1). Tablo 1'de görüldüğü üzere "eylemsel fayda ölçütü"; karar alıcının saha tecrübelerinden beslenir. Akla ve hayatın gerçeklerine dayanan bir eylemlilik halidir. "Değiş̧ebilirlik ölçütü"; maksat ve gayeden sapmamak kaydıyla, uygulanan araç ve yöntemlerin yeniden esnekliğine dayanır. "Amaçlılık ölçütü”; bir başarının ancak daha büyük bir amaca ulaşabilmek için bir araçtan ibaret görülmesidir. "İ̧se yarar çözüm üretme ölçütü"; maksat hâsıl olduğu sürece, işe yarayan çözümlere kiymet vermek, gereksiz yere zaman kaybetmemek anlamına gelir. "Mesele odaklı pragmatist akılcılık ya da stratejik pragmatizm ölçütü"; uygulamayı safhalara ayırmak, olgulardan yararlanarak fikren hazırlanmak ve adım adım yürüyerek hedefe varmaktır. Ayrıca tarihsel olayların biriktirdiği tecrübeye, kuramsal hakikat arayışı karşısında hayatın gerçekliğine inanmak, "deneyimlere dayanmak"; samimi ve meşru olmak kaydıyla her fikri değerli bulmak, "fayda-mahzur analizi"; gerçekleştirilebilir maksatların belirlenmesi, bu maksatların başarılması üzerine bir siyaset ve strateji belirlemek, "somut başarı kriterleri koymak" ve eylem ve uygulamanın sözden ve kuramdan önce

\footnotetext{
${ }^{46}$ Mustafa Kemal Atatürk, Nutuk, yay. haz. Zeynep Korkmaz. Atatürk Kültür, Dil ve Tarih Yüksek Kurumu Atatürk Araştırma Merkezi Yayınları, Ankara, 2005, s. 25.
} 


\section{Özgür KÖRPE}

178

Güvenlik Stratejileri

Cilt: 17

Sayı: 37 gelmesi, "sonuç odaklılık" olarak tanımlanmış ve "Stratejik Pragmatizm" özelliğinin alt katmanları olarak tanımlanmıştır.

\section{Tablo 1. Pragmatik Bilişsel Yapının Özellikleri}

\begin{tabular}{|c|c|c|}
\hline S. No. & Tanımlamalar & Ölçütler \\
\hline 1 & $\begin{array}{l}\text { Esas olarak tecrübelerden beslenen, aklın ve } \\
\text { gerçekliğin izinden giderek ulaşılmış bir hakikat } \\
\text { algısının yönlendirdiği eylemlilik hali }\end{array}$ & $\begin{array}{l}\text { Eylemsel fayda } \\
\text { ölçütü }\end{array}$ \\
\hline 2 & $\begin{array}{l}\text { Askerî başarının ancak daha büyük bir amaca } \\
\text { ulaşabilmek için bir araçtan ibaret görülmesi }\end{array}$ & Amaçlılık \\
\hline 3 & $\begin{array}{l}\text { Maksat hasıl olduğu sürece, işe yarayan çözümlere } \\
\text { kıymet vermek, gereksiz yere zaman kaybetmemek }\end{array}$ & $\begin{array}{l}\text { İşe yarar çözüm } \\
\text { üretmek }\end{array}$ \\
\hline 4 & $\begin{array}{l}\text { Uygulamayı safhalara ayırmak, olgulardan } \\
\text { yararlanarak fikren hazırlanmak ve adım adım } \\
\text { yürüyerek hedefe varmak }\end{array}$ & $\begin{array}{l}\text { Stratejik } \\
\text { pragmatizm }\end{array}$ \\
\hline \multirow{4}{*}{ 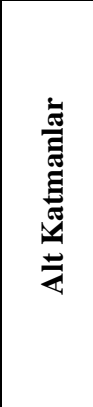 } & \begin{tabular}{l|l} 
a & $\begin{array}{l}\text { Tarihsel olayların biriktirdiği tecrübe, kuramsal } \\
\text { hakikat arayışı karşısında hayatın gerçekliği }\end{array}$
\end{tabular} & $\begin{array}{l}\text { Deneyimlere } \\
\text { dayanmak }\end{array}$ \\
\hline & \begin{tabular}{l|l} 
b & $\begin{array}{l}\text { Samimi ve meşru olmak kaydıyla her fikri değerli } \\
\text { bulmak }\end{array}$
\end{tabular} & $\begin{array}{l}\text { Fayda-mahzur } \\
\text { analizi }\end{array}$ \\
\hline & \begin{tabular}{l|l} 
c & $\begin{array}{l}\text { Gerçekleştirilebilir maksatların belirlenmesi, bu } \\
\text { maksatların başarılması üzerine bir siyaset ve } \\
\text { strateji }\end{array}$
\end{tabular} & $\begin{array}{l}\text { Somut başarı } \\
\text { kriterleri koymak }\end{array}$ \\
\hline & \begin{tabular}{l|l} 
ç & $\begin{array}{l}\text { Eylem ve uygulamanın sözden ve kuramdan önce } \\
\text { gelmesi }\end{array}$
\end{tabular} & Sonuç odaklılık \\
\hline 5 & $\begin{array}{l}\text { Maksat ve gayenin değil ama araç ve yöntemlerin } \\
\text { değiştirilebilirliği ve yeniden yorumlanabilirliği }\end{array}$ & Değişebilmek \\
\hline
\end{tabular}

Bu özellikler 1şı̆̆ında, hibrit bir meseleyi tanımlamaya soyunan bir karar alıcı, istenen son durumu belirlerken ve tüm tasarım sürecinin kontrolünde, pragmatik bilişsel yapının özelliklerinden yararlanabilir. Tablo 2, maksadın belirlenmesinde ve kontrolünde kullanılabilecek bir uyumluluk matrisi önerisi sunmaktadır. 
Türk Stratejik Kültüründe Çözümü Çerçevelemek:

Katmanlı Bir Harekât Tasarımı Önerisi

Tablo 2. Pragmatik Uyum Soruları Matrisi

\begin{tabular}{|c|l|}
\hline S. No. & \multicolumn{1}{|c|}{ Kontrol Soruları } \\
\hline $\mathbf{1}$ & Harekâtın maksadı eylemsel faydayı sağlıyor mu? \\
\hline $\mathbf{2}$ & Harekâtın maksadı stratejik amaca uygun mu? \\
\hline $\mathbf{3}$ & Harekâtın maksadı işe yarar çözüm üretiyor mu? \\
\hline \multirow{2}{*}{4} & Çözüm hal tarzı deneyimlere dayanıyor mu? \\
\cline { 2 - 3 } $\mathbf{4}$ & Çözüm hal tarzı fayda-mahzur analizine imkân veriyor mu? \\
\cline { 2 - 3 } & Çözüm hal tarzı somut başarı vadediyor mu? \\
\cline { 2 - 3 } & Çözüm hal tarzı sonuç odaklı mı? \\
\hline \multirow{2}{*}{} & Çözüm hal tarzı değiştirilebilir mi? \\
\hline
\end{tabular}

179

Güvenlik Stratejileri

Cilt: 17

Say1: 37

\section{Güncel Kötü Meseleleri Tanımlamadaki Eksiklik}

Maksatlı pragmatik eylemin çıkış noktası olan "karmaşıklığın" kontrol altına alınmasını, bu sayede kötü meselenin tanımlamasını ve çözülmesini esas alan EOH ve sistem yaklaşımı, ortaya çıktığı 1980'lerden bu yana kendi içinde farklı yöntemler geliştirmiştir. Bugün, meselenin çerçevelenmesi ya da daha açık bir ifadeyle harekât tasarımı için, askerî doktrinde Reilly'nin zihin haritalama yöntemi benimsenmişse de yöntemler bununla sınırlı değildirler. Esasen yöntemlerin sayısı, insan zekasının yaratıcılı̆̆ıyla sınırlıdır. Harekât tasarımında önemli olan, meseleyi tanımlayabilecek bir benzeşim modeli kurabilmektir. Ancak, aşağıda sunulan modellerin de bu konuda etkinliği denenmiş ve kabul görmüş olduklarını unutmamak ve bunları yok saymamak gerekir.

Örneğin Kem'in Eleştirel Akıl Yürütmeye Dayanan Mesele Çözme yaklaşımına göre harekât tasarımı; planlayıcıların bir muharebeyi kazanmak için gerekli tüm eylemleri dikkate almalarına yardımcı olmak maksadıyla geliştirilmiştir. Tasarım faaliyetleri; "mevcut bağlamı anlamak"; "gelecekteki bağlamı veya istenen son durumu 


\section{Özgür KÖRPE}

180

Güvenlik Stratejileri

Cilt: 17

Sayı: 37

görselleştirmek" ve "mevcut ortamı istenen son duruma dönüştürmek" maksadıyla, mevcut ile istenen durum arasındaki boşluğu dolduran operatif bir yaklaşım veya bir eylem teorisi geliştirmektir. Kem, meseleyi belirlemek için kullanılan eleştirel muhakemeyi, çözümü belirlemek için kullanılan yaratıcı düşünceden ayırır ve meseleyi belirlemek için üç temel soru sorar: Mesele nedir? Çözüm nedir? Çözüm meseleyi karşılayabiliyor mu? ${ }^{47}$

ABD askerî yayınları olan FMI 5-2 Design ve FM 3-0 Operations'daki tasarım yaklaşımında; mesele çerçeveleme, bir çözüm yaratma, değerlendirme ve yeniden çerçevelendirmeyi içeren üç aşamalı bir metodoloji ana hatlarıyla ortaya koyulmuştur. ${ }^{48}$

Franks, Çizgiler ve Dilimler yaklaşımında, meseleyi tanımlamak için matris gösterimden yararlanmayı önerir. Matristeki yatay çizgiler harekât hatlarını ve dikey dilimler hedefleri veya ağırlık merkezlerini içerir. $\mathrm{Bu}$ yapıda örtük olarak, tüm hedef kümelerini etkilemenin vazifenin maksadını gerçekleştireceği ve istenen son durumu tesis edeceği fikri vardır. ${ }^{49}$

Warden'ın Beş Halka yaklaşımı; diğerlerine kıyasla çok genel bir tasarım olmasına rağmen, yine de harekât için bir yapı gösterir. İç içe geçmiş halkalardan oluşan modelde, merkezdeki daireye baskı uygulamanın hedeflerin elde edilmesini sağlayacağı ve böylelikle istenen son duruma ulaşılacağ 1 iddia edilir. ${ }^{50}$

Mattis'in Gayret Birliği yaklaşımına göre, komutanları ve planlamacıları AKVES adımlarına aşırı bağımlı kılmak yerine; onların

\footnotetext{
${ }^{47}$ Jack D. Kem, Campaign Planning: Tools of the Trade (Department of Joint and Multinational Operations), U.S. Army Command General Staff College, Kansas, USA 2002, p. 1.

${ }^{48}$ FMI 5-2 Design, Department of Defense, Washington DC, USA, 2009, p. i; FM 3-0 Operations, Department of Defense, Washington DC, USA, 2017, p. 6-6.

${ }^{49}$ Tommy R. Franks, American Soldier, William Morrow Paperbacks, New York, NY, USA 2005, p. 527.

${ }^{50}$ John A. Warden III, “The Enemy as a System," Airpower Journal, Airpower Journal sitesi www.airpower.maxwell.af.mil/airchronicles/apj/apj95/spr95files/warden.htm, (Erişim Tarihi 28.12.2020).
} 
Türk Stratejik Kültüründe Çözümü Çerçevelemek:

Katmanlı Bir Harekât Tasarımı Önerisi

karmaşık meseleleri tanımlamalarına yardımcı olmak için, harekât tasarımını doktrine yerleştirmek ve benimsetmek gerekir. ${ }^{51}$

Bugün askerî doktrin tarafından benimsenmiş olan Reilly'nin tasarım modeli (Şekil 2) ise, zihin haritalamayı esas alır. Reilly'nin modelinin odak noktasının ağırlık merkezlerine yapılacak etkiler olduğunu hatırlatmak yeterli olacaktır. Ancak bu model, düşman ağırlık merkezlerine odaklanmanın dışında, günümüzün hibrit meseleler ortamında ihtiyaç duyulan "strateji ve görev arasındaki bağlantıdan" yoksundur. Dolayısıyla model, teşkilatı ve yapısı bilinen bir hasma karşı etkilidir. Diğer bir deyişle kritik kabiliyetler, kritik ihtiyaçlar, kritik hassasiyetler yaklaşımını esas alan ağırlık merkezi analizi, ancak ve ancak somutlaştırılabilen bir hasma karşı sonuç verebilir. Ancak amorf ve değişken, ağırlık merkezi tespit edilemeyen bir hasma karşı uygulanması zorlaşmakta, modele yeni bir katman ilave edilmesine ihtiyaç duyulmaktadır. Kaldı ki karşılaşılan meselelerdeki örtük nedenselliği ortaya çıkartabilmek için haritalamanın katmanlı hale getirilmesi gerektiğini savunan yazarlar da bulunmaktadir. $^{52}$

\footnotetext{
${ }^{51}$ Mattis, a.g.e.

${ }^{52}$ Gerard P. Hodgkinson ve A. John Maule, "The Individual in the Strategy Process: Insights from Behavioural Decision Research and Cognitive Mapping" Anne S. Huff, Mark Jenkins, (ed.), in Mapping Strategic Knowledge, Sage Publishing, Thousand Oaks, CA, USA, 2002, 196-219, p. 197.
}

\section{1}

Güvenlik Stratejileri

Cilt: 17

Say1: 37 
182

Güvenlik Stratejileri

Cilt: 17

Say1: 37

Şekil 2. Reilly'nin Ağırlık Merkezi Odaklı Zihin Haritalaması $^{53}$

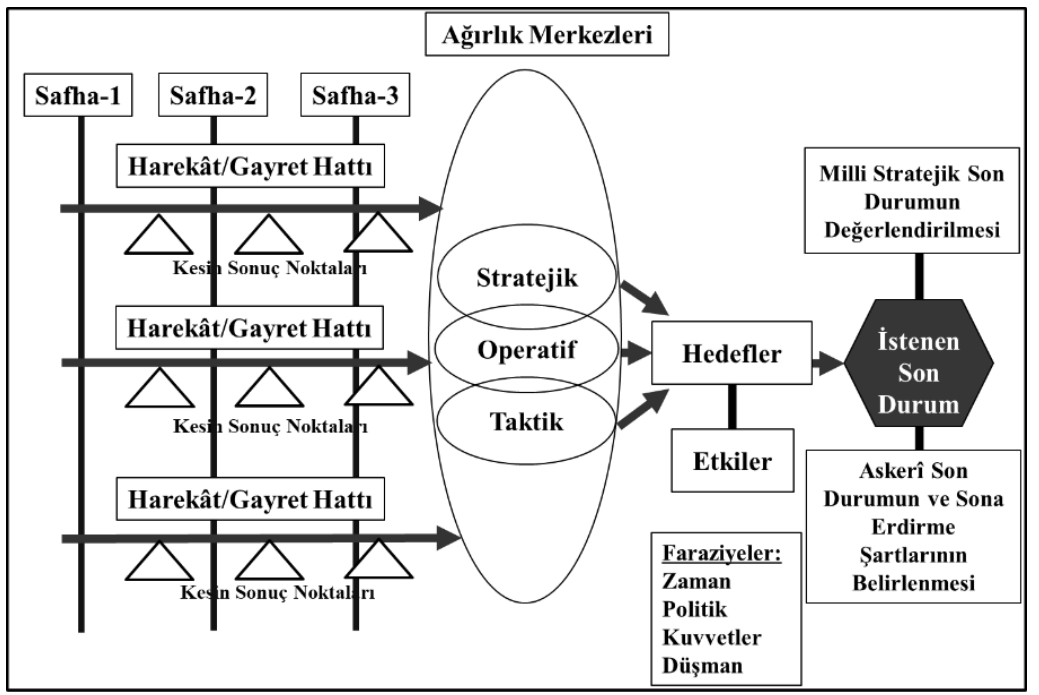

Modelin bir diğer eksikliği; konjonktürel nedenlerle, görevler ve kesin sonuç noktalarından (KSN) istenen son duruma ulaşmadaki mantıksal bağlantıyı kurma ihtiyacı duymamış olmasıdır. Zira model ağırlık merkezlerini harekât hatları ile hedefler arasına yerleştirerek; ağırlık merkezleri ile harekât hatları ve askerî hedefler arasında lineer bir bağlantı oluşturmaktadır. Ancak lineer bağlantı günümüzde iyice karmaşıklaşmış ve bulanıklaşmış olan operatif ve stratejik seviyedeki meselenin anlaşılması için yeterli değildir. Bunu yürürlükteki doktrinden de görmek mümkündür. Hatırlanacağı üzere, harekât hatları her ne kadar KSN'leri yer ve zamanca ağırlık merkezlerine bağlasalar da etki etmek için değil, hedefleri elde etmek için geliştirilirler. Zira hedefler kritik hassasiyetlerden üretilir. Hedef, bazen istenen etkidir, bazen de

\footnotetext{
${ }^{53}$ Reilly, a.g.e., s.32.
} 
Türk Stratejik Kültüründe Çözümü Çerçevelemek:

Katmanlı Bir Harekât Tasarımı Önerisi

harekâtın fiziki sonucudur. Her seviyedeki harekât açıkça ifade edilmiş, erişilebilir ve sonuç getirici hedeflere yöneltilir. ${ }^{54}$ Hatta operatif seviyedeki komutan taktik seviyedeki astlarına KSN'leri birer hedef olarak verir. Nitekim taktik seviyede harekât hatları hedefe coğrafi istikametler kullanarak ulaşmak anlamına gelir. Diğer bir deyişle ağırlık merkezi odaklı zihin haritası, hem hedeflerin net olarak belirlenmesini önermekte hem de bu önerisiyle çelişerek, hedefleri şablonda ağırlık merkezlerinin ötesine konumlandırmaktadır. Bunu bu lineer şablonda gösterebilmek de zordur. Bakış açısını lineerden, çok katmanlı bir hale getirmek, bu konuda bir çözüm sunabilir. Çünkü hibrit meselelerin sofistike doğası yüzünden, harekâtın her safhasında yeni yöntemler ve tehditlerle karşılaşılabilir. Bu durumda lineer mantık yerine, katmanlı mantık kullanmak daha pragmatik olacaktır.

Askerî doktrin, kritik hassasiyetler tespit edilemediğinde, kritik ihtiyaçlara etki edilerek hassasiyet yaratılmasını ve bir ağırlık merkezi tespit edilememesi durumunda da harekât hatlarının doğrudan istenen son duruma bağlanmalarını önermektedir. ${ }^{55}$ Yani komutan gerektiğinde doğrudan amacına ulaşabilecek bilişsel hatlar tesis edebilmelidir. Ancak harekât hatlarının geliştirilmesi ağırlık merkezi analizine bağımlıdır. $\mathrm{Bu}$ nedenle de harekât hatları ağırlık merkezinden çıkarılan kritik hassasiyetlerin kullanılması yöntemiyle oluşturulurlarsa, doğal olarak ağırlık merkezlerine etki edemezler. Öte yandan ağırlık merkezlerinin imhasının belli bir hedefin elde edebileceğinin ve hatta bazen bir ağırlık merkezi tespit edilebileceğinin dahi garantisi yoktur. Bu öneri de bir kez daha hedeflerin ağırlık merkezlerinin berisinde belirlenmesi gerekliliğini ortaya koymaktadır. Zira ancak ve ancak kritik hassasiyetleri istismar edilmesini sağlayacak hedefler elde edilince, harekât istenen son duruma ulaşmış olur. $\mathrm{Bu}$ yüzden de ağırlık merkezlerini harekât hatlarıyla hedeflerin arasına yerleştiren lineer bakış açısı, eylemsel faydanın sağlanması bakımından eksik kalmış bir bilişsel süreçtir.

\footnotetext{
${ }^{54}$ FM 5-0, Operations Process, pp. xix, IV-19.

${ }^{55}$ A.g.e., s. xxiii, VI-29.
}

\section{3}

Güvenlik Stratejileri

Cilt: 17

Say1: 37 
Özgür KÖRPE

184

Güvenlik Stratejileri

Cilt: 17

Sayı: 37

\section{Hibrit Tasarım Önerisi: Lineer Yerine Katmanlı}

Reilly'nin ağılık merkezi odaklı zihin haritalama yaklaşımında, hibrit savaş çerçevesinde yukarıda tespit edilen iki eksiklik, çok katmanlı tasarım modelinin de fikrî çıkış noktasını oluşturmaktadır. Yukarıda da vurgulandığ gibi, karmaşıklı̆g tanımlamada yetkin bir yöntem olan sistem yaklaşımının, bir adım ileride, bulanıklığı tanımlamada yetersiz kaldığı yanlar bulunmaktadır.

Daha önce de açıklandığı gibi, muharebe sahasında karşılaşılan bütün meseleler içinde, sadece taktik seviyedekiler iyi yapılandırılmış meselelerdir. Meseleler, operatif ve stratejik seviyelere çıkıldığında, "kötü meseleler" haline gelirler. Günümüzün harekât ortamında bu kötü meseleler, hibrit bir hal almışlardır. Bu bilgiler 1şığında, hibrit meselelerin tanımlanmasında çok katmanlı bir yaklaşım gerektiğini tekrar vurgulamak gerekir. Askerî doktrin de katman niteliğinden bahsetmese de harekât tasarımında eşzamanlı üç adım olduğunu belirterek, hibrit bir yaklaşıma kolaylık sağlıyor. Askerî doktrinin önerdiği üç adım;

* Ortamı çerçeveleme,

* Meseleyi çerçeveleme ve

* Harekât yaklaşımlarını değerlendirmedir. ${ }^{56}$

$\mathrm{Bu}$ çalışmada, çok katmanlı tasarım için askerî doktrinin bu üç adımından yararlanılmıştır. Birinci adım, yani harekât ortamını çerçevelemek, karmaşık bir gerçekliği anlamlandırmayı içermektedir. Bu çalışmanın önerdiği tasarımda öncelikle, pragmatik düşüncenin denge merkezi olduğu Şekil 1'deki genel fikrî çerçeve, temel altlık olarak çizilir. Ardından da ortamın çerçevelenmesine başlanır. Müşterek Harekât Bölgesi İstihbarat Hazırlığı (MHBİH) biçimindeki bir sistem analizi; durumun doğru bir şekilde anlaşılmasını sağlamak için ilgili aktörleri ve bunların aralarındaki ilişkileri düzenler, gruplandırır ve tanımlar.

Günümüz harekât ortamı, lineer sistem yaklaşımının geliştirildiği döneme kıyasla daha da karmaşık olduğundan; mevcut askerî doktrin,

${ }^{56}$ FM 5-0, Operations Process, p. 3-7; Schmitt, a.g.e., s. 20-23. 
Türk Stratejik Kültüründe Çözümü Çerçevelemek:

Katmanlı Bir Harekât Tasarımı Önerisi

muhasım tarafların tüm düzenli birliklerinin teşkilat ve tertiplenmelerini büyük ölçüde muhafaza ederek muharebe edecekleri faraziyesine dayanır. Doktrinin esas aldığı harekât ortamı, askerî harekâtın başrol olma niteliğini kaybetmediği ve fakat bu harekâtın maksadının tahakkukunu etkileyen yeni fenomenlerin ortaya çıktığı bir dünyadır. Böyle bir harekâtın MHBİH'nde, hasım sistemindeki kritik kabiliyetleri, kritik ihtiyaçları, kritik hassasiyetleri ve kesin sonuç noktalarını ortaya koyarak, ağırlık merkezlerini belirleyen bir kritik faktör analizi yapılabilir.

Ancak, hibrit harekât ortamı böyle değildir. EOH'da kullanılan dost ve hasım ağırlık merkezlerinin belirlenmesindeki kritik kabiliyetler, kritik ihtiyaçlar, kritik hassasiyetler yöntemi, hibrit meselelerin sofistike ve spontane karakteristiğine uygun değildir. Zira bu siralama, somut bir biçimi olan bir hasmın kabiliyetleri, ihtiyaçları ve hassasiyetlerini esas alır. Hasmın evsafının net olmadığı durumda, etki edilebilecek bir ağırlık merkezi de bulunamayacaktır. Diğer bir deyişle, istihbarat geliştiricilerinin yapacakları sistemler sistemi analizi, PASEBA'y1 ${ }^{57}$ yönlendirmekte yetersiz kalabilecektir.

Karar alıcı ağırlık merkezi tespitiyle vakit harcamak yerine, ortamı kendi maksat ve gayesine uyumlu hale getirmeye odaklanmalıdır. Bu yaklaşım Türk Stratejik Kültürünün pragmatik niteliğini ortaya koyan "Eylemsel fayda", "amaçl1lık" ölçütlerine uygundur. Bu durumda ilk aşamada bir ağırlık merkezi seçilmeli ve onun neden bir ağırlık merkezi olması gerektiği savunulmalıdır. ABD'de bu yöntem "Seç ve Savun Yöntemi”" olarak subaylara öğretilmektedir. ${ }^{58}$ Müteakip aşamada; ortamdan çıkartıldığında veya üzerine etki edildiğinde ortamdaki birtakım aktörleri rahatsız eden kabiliyetler ve ihtiyaçlar, hassasiyet olarak belirlenmelidir. Askerî doktrin de benzer bir öneriyi EOH yaklaşımı için yapmaktadır.

\footnotetext{
${ }^{57}$ PASEBA, stratejik ve operatif seviyede sistemler sistemi analizinde kullanılan bir formülasyondur. Politik, Askerî, Sosyal, Ekonomik, Bilgi, Altyapı sistemlerinin analizine işaret eder.

58 Joe Strange ve Richard Iron, Understanding Centers of Gravity and Critical Vulnerabilities, Department of War Studies, Swedish National Defence College 2005, p. 7.
}

\section{5}

Güvenlik Stratejileri

Cilt: 17

Say1: 37 


\section{Özgür KÖRPE}

186

Güvenlik Stratejileri

Cilt: 17

Sayı: 37

Diğer bir deyişle ortama etki yapılmalı ve etkinin dalgaları ya da etkiye karşı tepkiler takip edilmelidir. Böylece, planlamaya ayrılması gereken ve fakat ağırlık merkezlerinin tespiti için gereksiz yere harcanan zamandan tasarruf edilmiş olur. Bu araştırmada önerilen ikinci aşama "Dalga Etkisi” olarak adlandırılmıştır. Warden'ın Beş Halka Modelinden yararlanılarak, harekât tasarımına Şekil 3'teki gibi bir Dalga Etkisi şablonuyla başlanabilir.

\section{Şekil 3. Ağırlık Merkezi Tespitinde Dalga Etkisi Şablonu}

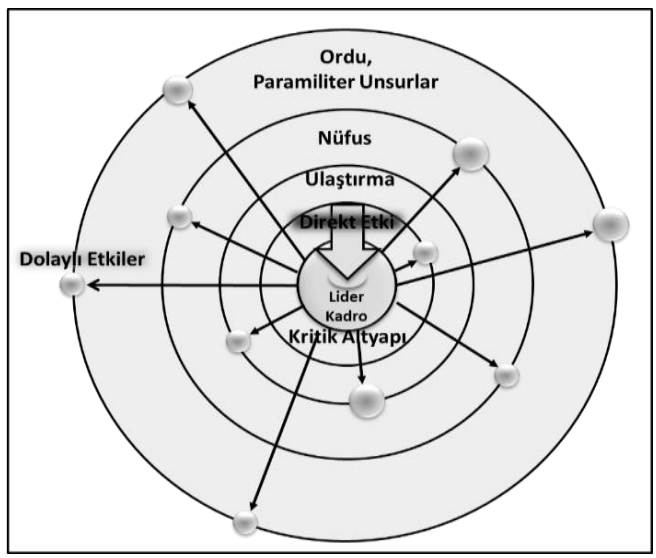

Ancak ağırlık merkezi analizi meselesi bu kadarla bitmiyor. Eksik olan, stratejik seviye ile operatif ağırlık merkezlerini birbirine bağlamaktır. Ağırlık merkezlerini bu şekilde konumlandırmak, kritik hassasiyetlerden üretilen hedeflere yapılacak etkileri de netleştirecektir. Zira günümüzde ordular, genellikle topyekûn harp düzeyine ulaşmayan çatışmalara girmektedirler. Artık, güç unsurlarının baş rol oynama önceliklerinin değiştiği hibrit bir çatışma ortamı bulunmaktadır.

Bilindiği üzere yüksek stratejide uygulanan birçok yöntem vardır. Bunlar; şekillendirme, caydırma ve zorlama olarak adlandırılır. $\mathrm{Bu}$ stratejilerin her biri çeşitli mekanizmalar kullanırlar. Sözgelimi şekillendirme; etkileme, dengeleme ve imkân sağlama mekanizmalarını kullanır. Caydırıcılık, doğrudan veya dolaylı mekanizmaları kullanabilir. 
Türk Stratejik Kültüründe Çözümü Çerçevelemek:

Katmanlı Bir Harekât Tasarımı Önerisi

Zorlama; yıpratma, imha ve baskı altına alma gibi mekanizmaları kullanır. Strateji geliştirme, ağırlık merkezlerinin belirlenmesi için oldukça faydalıdır ve stratejik kültürle yakından ilişkilidir. Zira strateji geliştirmede karar alıcının operasyonel kodları belirleyicidir. Örneğin, güçlü taarruzi operasyonel kodlara sahip olan bir karar alıcı sırasıyla; zorlama $>$ dengeleme $>$ etkileme mekanizmalarına başvuracaktır ${ }^{59}$. Keza Feng de Çin stratejik kültüründeki diyalektiği operasyonel kodlarla açıklamıştır ${ }^{60}$. Bunun nedeni, her stratejinin ve bunlarla ilgili stratejik mekanizmanın bir ağırlık merkezine uygun düşme ihtimalinin yüksek olmasıdır. Diğer bir deyişle stratejik biliş düzeyi, etkilerimizin nereleri hedef alması gerektiğini belirler. Bir strateji seçildikten ve bu strateji bir mekanizmaya bağlandıktan sonra, kritik hassasiyetleri ortaya çıkarmak için, kritik faktör analizi yöntemiyle ağırlık merkezi analizi yapılması mümkün hale gelir. Hibrit savaşta, birden fazla strateji, mekanizma veya yöntemin kullanılabileceği de unutulmamalıdır. $\mathrm{Bu}$ yaklaşım Türk Stratejik Kültürünün pragmatik niteliğini ortaya koyan "somut başarı kriterleri koymak" ve "deneyimlere dayanmak" ölçütlerine uygundur.

Doktrin ağırlık merkezi analizinde, kritik hassasiyetleri belirlemenin bir yolu olarak kritik faktör analizini önermektedir. ${ }^{61}$ Ancak, günümüzde kritik kabiliyetler, kritik ihtiyaçlar ve kritik hassasiyetler arasında anlaşı1ır bir mantıksal bağlantı kurmaya ihtiyaç vardır. Kritik faktör analizinde bilinen dörtlü matris, iteratif mantığ1 nedeniyle, sistem yaklaşımına dayanan $\mathrm{EOH}$ için yeterliyken, hibrit savaşın iteratif olmayan niteliği nedeniyle; kritik kabiliyetleri, kritik ihtiyaçlara ve ardından kritik hassasiyetlere bağlamak zorlaştırmıştır. Dolayısıyla dörtlü matris, bağlantıyı bir unsurdan diğerine aktarmada yetersiz olmaktadır ve kritik faktörler bağımsız birer beyin firtınası

\footnotetext{
59 Stephen G. Walker, "The Motivational Foundations of Political Belief Systems", International Studies Quarterly, c. 27. 1983, 179-201.

${ }^{60}$ Huiyun Feng, "The Operational Code of Mao Zedong: Defensive or Offensive Realist”, Security Studies, c. 14 (4), October-December 2005, 637-662, p. 649.

${ }^{61}$ FM 5-0, Operations Process, p. IV-23.
}

\section{7}

Güvenlik Stratejileri

Cilt: 17

Say1: 37 


\section{Özgür KÖRPE}

188

Güvenlik Stratejileri

Cilt: 17

Say1: 37

faaliyetleri gibi algılanmaktadır. Öyleyse hibrit meselelerde iterasyonların yakalanamadığı durumlarda, yaratıcılığın devreye sokulması ve analizin yenilenmesi gerekmektedir. Dörtlü matrise ilave olarak ve hatta gerektiğinde onun yerine, ağırlık merkezi analizinin katmanlarını gösteren aşağıdaki gibi bir şeklin (Şekil 4) doktrine dâhil edilmesinin, kritik faktör analizinin ve kritik faktörler arasındaki doğru bağlantının daha iyi kurulmasını sağlayabileceği değerlendirilmektedir.

Şekil 4. Ağırlık Merkezi Analizinin Katmanları

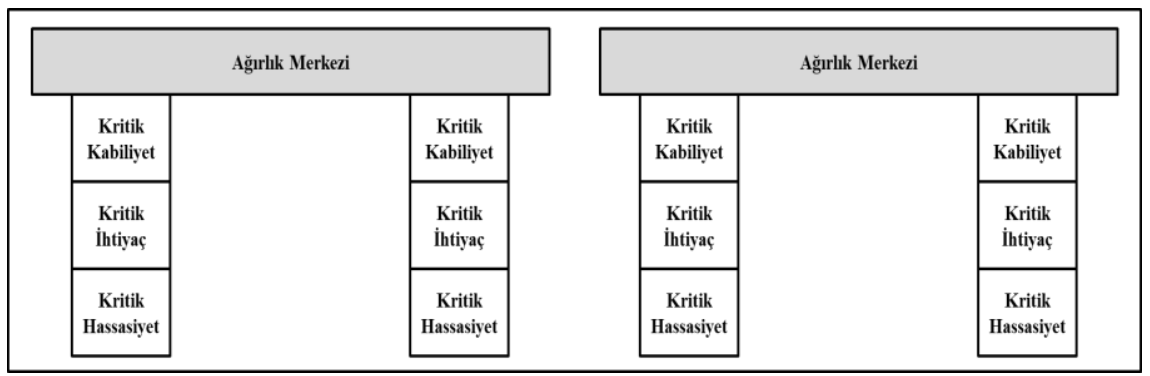

Şekil 4'te görüldüğü üzere faktörler; birkaç sütundan oluşan bir yapının tuğlaları gibi, birbirlerinin tamamlayıcısıdırlar. Ağırlık merkezleri kritik kabiliyetlerle işlerlik kazandıklarından, kritik kabiliyet yoksa, zaten hasmın taktik açıdan bir değeri de olmayacaktır. Kritik ihtiyaçlar ise kabiliyetlerin varlıklarını sürdürebilmeleri için gereklidirler. İstismar edilmeye açık olan kritik ihtiyaçlar da hassasiyetleri oluştururlar. Çekilen tuğla, kendisinden sonrakini devirecektir. Neticede ortamın şekillendirmesi sonucunda harekât tasarımının birinci önerilen katmanı oluşmuş olur (Şekil 5). 
Türk Stratejik Kültüründe Çözümü Çerçevelemek:

Katmanlı Bir Harekât Tasarımı Önerisi

Şekil 5. Ortamı Çerçevele

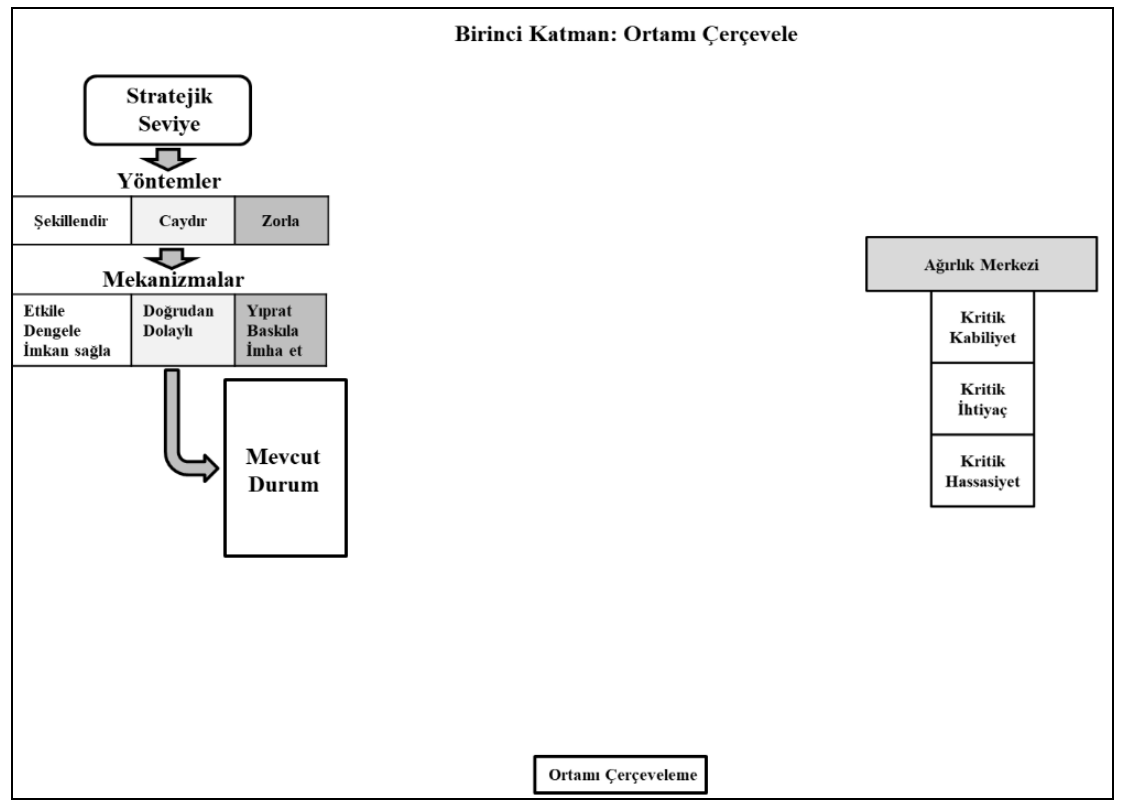

Güvenlik Stratejileri

Cilt: 17

Say1: 37

Hibrit ortamda harekâtta sadece ağırlık merkezlerinin tespitine odaklanmak da yeterli değildir. Çünkü hasım ağırlık merkezlerinin analizi, hasmın ağırlık merkezlerinin belirlenebildiği durumlarda sonuç verir. Ancak hasmın evsafının tam olarak tanımlanamadığ 1 durumlarda tek başına ağırlık merkezi analizi yeterli olmaz. Diğer taraftan bu tespit karar alıcıyı, hasmı etraflıca tanımlaması gerektiği gibi bir düşünceye yönlendirebilir. Dolayısıyla meselelerin hibrit nitelikli olduğu harekât ortamında hasmın ağırlık merkezlerinin ne olduğunu belirlemeye çalışmak, boşa giden bir gayret de olabilir. Bu çalışma bu noktada aşağıda detayları sunulan pragmatik düşünceden yararlanmayı önermektedir.

Öncelikle ortam hibritse, çerçevelenmesi bilakis açıklayıcı olmalıdır. Zira yukarıda ortaya koyulan ortamın çerçevelenmesi; sonlandırma kriterleri, istenen son durum, hedefler ve etkiler dâhil olmak üzere, ana fikrin incelenmesini ve sentezlenmesini de gerektirir. 

Bununla birlikte, kötü meselelerin çözümünde kesin bir formül olmadığından, bulanık veya belirsiz bir ana fikir ortaya çıkabilir. $\mathrm{Bu}$ nedenle, bu aşamada harekât tasarımının eş zamanlı ikinci adımının da devreye sokulması gerekir ki; bu da meselenin çerçevelenmesidir.

Meselenin çerçevelenmesi, onun temel nedenlerini izole etmek için ortam çerçevesini iyileştirmeyi içerir. Bir harekât meselesini anlamak, onu üreten bağlamın anlaşılmasını gerektirir. Bununla birlikte harekât tasarımı hem kötü meselelerin hem de operasyonel ortamı oluşturan karmaşık, uyabilen yapıların bilinmeyen doğasını anlamayı sağlar. Schmitt'in tespit ettiği gibi, kötü bir meseleyi anlamak demek; gerçekliği yeterince doğru bir şekilde yakalamaktan ziyade, bu gerçeklikle başa çıkabilecek faydalı bir yorum yapabilmek demektir. ${ }^{62}$ Meseleyi çerçevelemenin ilk ve en önemli adımı ise meselenin ne olduğunu belirlemektir. Askerî planlamacılar için bu, istenen son durumdur ve vazife tahlili sonucunda belli olur. Bir istenen son durum belirlendiğinde, buna ulaşmak mesele haline gelmiş olur.

İstenen son durum belirlendikten sonra hedefler belirlenmelidir. Ağırlık merkezleri tespit edilebildiyse, kritik hassasiyetlerden hedefleri üretmek kolaydır. Hedefler, ağırlık merkezlerinde yaratacakları etkiler ve bu etkilerin istenen son duruma ulaşmayı sağlayıp sağlayamayacağı belirlenerek doğrulanmalıdır. EOH'ta, karar alıcılar meseleyi çerçevelendirirken, istenen son durum ile çevre ve hasmın sistemleri arasındaki ilişkiyi daha ayrıntılı olarak araştırırlar. İstenilen son durumla ilişkili oldukları için sistem eğilimlerinin değerlendirilmesi çok önemlidir. Bu bilgi arttıkça, tasarımcılar sistemin mevcut koşulları istenen koşullara dönüştürme potansiyeline sahip bölümlerini belirlerler. ${ }^{63}$ Ancak hibrit meseleyi tanımlayan bir karar alıcı, hasmın durumunun ne olduğunu ortaya çıkarmadan önce veya bununla eş zamanlı olarak, kendi maksatlarına odaklanmalıdır. Bu bağlamda istenen son durumun tespitine eskisine nazaran daha fazla önem verilmeli, konvansiyonel harekâtın

\footnotetext{
${ }^{62}$ Schmitt, a.g.e., s. 9-10.

${ }^{63}$ A.g.e., 14.
} 
Türk Stratejik Kültüründe Çözümü Çerçevelemek:

Katmanlı Bir Harekât Tasarımı Önerisi

standart "maksat" kalıplarına bağımlı kalmaktan kaçınılmalıdır. Vazife tahlilinin ortaya koyduğu, istenen son durum ve hedefler, harekât hatlarıyla birleştirildiği ve maksadın pragmatik uyumluluğunun yapıldığı meselenin çerçevelenmesi süreci sonunda ikinci adım tamamlanmış olur.

Üçüncü adımda, tasarımcılar genel harekât yaklaşımını

\section{1}

Güvenlik Stratejileri

Cilt: 17

Say1: 37 geliştirirler ve birinci katmanın üzerine oturturlar (Şekil 6a ve Şekil 6b). Doktrine göre bu, istenen son durumu tanımlayan koşulları üretecek genel eylemlerin geniş bir kavramsallaştırmasıdır. ${ }^{64}$ Harekât yaklaşımı, görevlerin özgün bir birleşimini ve bu görevleri istenen sonuca bağlayan mekanizmayı açıklar. Doktrin, tasarımın diyagramlar, kavram haritaları ve şekillerle görselleştirilmesini önermekte, bugün de karar alıcılar önerilen bu yöntemi, bu makalede de gösterildiği gibi, zihin haritalama şeklinde kullanmaktadırlar. Hibrit ortamda harekât yaklaşımları geliştirilirken, harekât hatları hedefleri ele geçirecek şekilde belirlenmeli, hedeflerin ele geçirilmesinin ağırlık merkezlerine etkiye veya onların imhasına sağlayacağı eylemsel fayda göz ardı edilmemelidir. Meselenin tanımlanmasındaki kesin sonuç noktaları ve bunları bağlayan harekât hatlarının gösterimindeki safhalı mantık muhafaza edilmelidir. Harekât yaklaşımı, ağırlık merkezlerine yapılacak etkiyi gösterirken, bu etkilerin nasıl yapılacağı hususunu, hareket tarzlarının geliştirildiği durum muhakemesine bırakır ki bu safhadan sonra operatif sanatın uygulanması başlar.

\footnotetext{
${ }^{64}$ FM 5-0, Operations Process, p. IV-30.
} 
Özgür KÖRPE

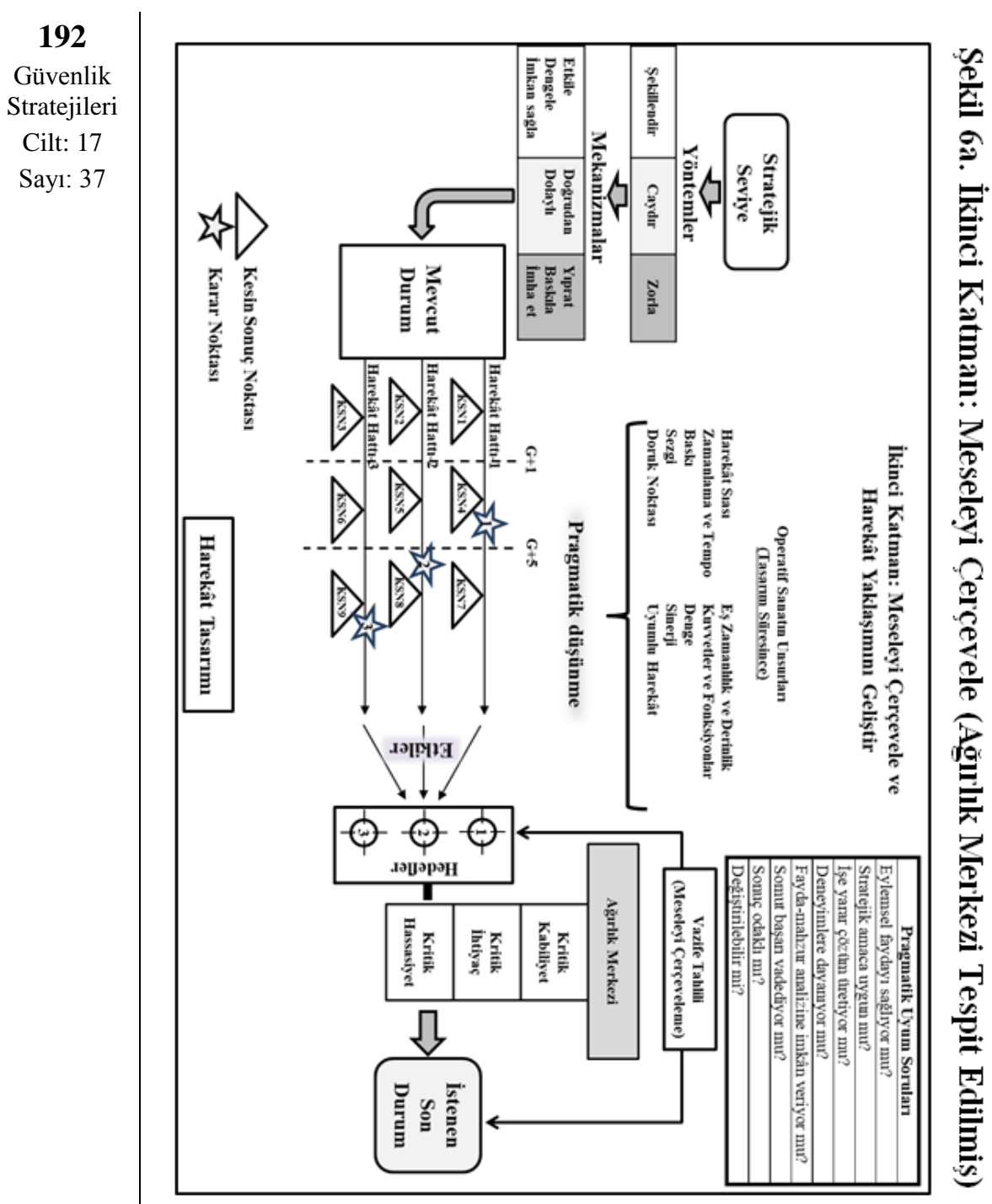


Türk Stratejik Kültüründe Çözümü Çerçevelemek:

Katmanlı Bir Harekât Tasarımı Önerisi

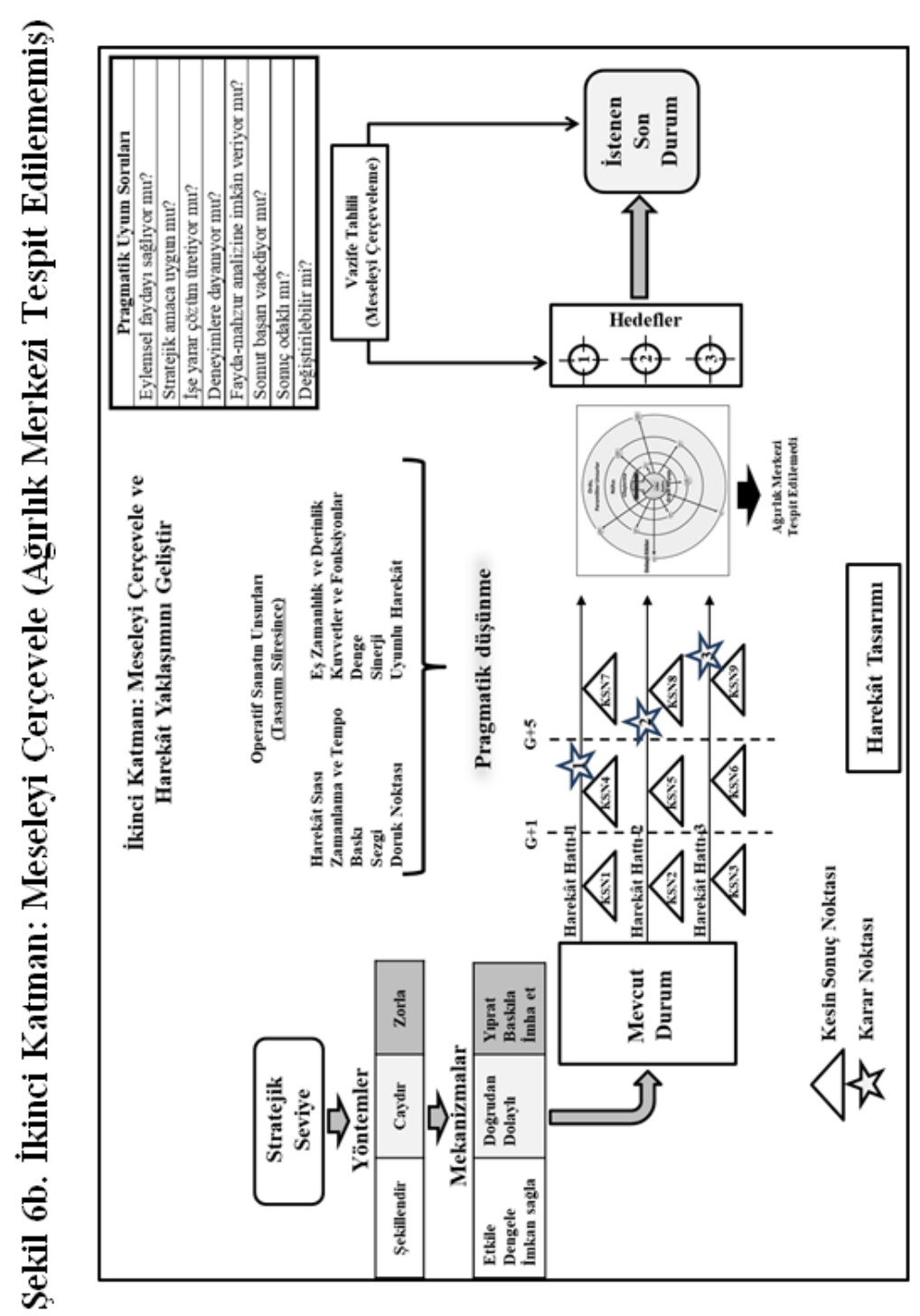

193

Güvenlik

Stratejileri

Cilt: 17

Say1: 37 
194

Güvenlik Stratejileri

Cilt: 17

Sayı: 37

Doktrin EOH'ta harekât tasarımı için "yeniden çerçeveleme" şeklinde son bir adım önermektedir. ${ }^{65}$ Yeniden çerçeveleme, "mevcut harekât yaklaşımını destekleyen önceki tasarım hipotezlerini, sonuçlarını ve kararlarını yeniden gözden geçirme sürecidir." ${ }^{\text {"66 }}$ Zira karmaşık uyabilen sistemlerin ve bunların yol açtığı kötü meselelerin tam olarak anlaşılmaması muhtemeldir ve doğru olarak anlaşılmaları zaman alabilir. Sürekli değerlendirme ve derinlemesine düşünme; ortam, mesele ve yaklaşım hakkında daha derin bir kavrayış da sağlar. Gerektiğinde, etkili eylemi optimize etmek için tasarım süreci yeniden başlatılmalıdır. EOH'nın önerdiği yeniden çerçeveleme, hibrit ortamda harekâtta katmanlı bir yaklaşımla yaratıcı bir şekilde uygulanabilir. Öte yandan hibrit bir meselede, karar alıcılara, en azından meselenin nasıl tanımlanabileceğine dair tasarım önerileri de sunmak gerekecektir. Bu bağlamda ağıllı merkezlerinde etkinin nasıl yapılacağı hususu, hedeflerle ağırlık merkezlerini birleştirecek şekilde netleştirilmelidir. Durum muhakemesi çıktıları oldukça da tasarımın bu son katmanına ilave edilmesinde, böylece kötü meselenin yeniden çerçevelenmesinin kolaylaştırılmasında yarar vardır.

Şekil 6a ve Şekil 6b, ağırlık merkezinin tespit edildiği bir hibrit ortamda, ikinci katmanın tamamlanması sonucunda oluşan vazife tahlili, harekât tasarımı ve operatif sanat arasındaki ilişkiyi de göstermektedir. Ancak, hibrit savaşın sofistike ve spontane niteliğinden dolayı, böyle bir ortamdaki meselenin tanımlanması ya da harekâtın hibrit tasarımının görselleştirilmesinde, belli kalıplara tabi olmak hatalı olur. Bu araştırmada ortaya koyulan model, özünde bir öneridir. Ası1 dikkat çekilmek istenen ise modelin kendisi değil; tasarımın, ortamı, meseleyi ve çözümü çerçeveleyebilecek kadar yaratıcı olmasıdır. Bu yüzden şablonların tüm parçalarını yerli yerine oturtmaya çalışmak yerine, asgari faktörün görselleştirilmesi ve birbirinin üstüne bindirilen yaratıc1 ve katmanlı zihin haritaları kullanılması her zaman daha işlevsel olacak ve pragmatik yaklaşımın ruhuna da sadık kalacaktır.

\footnotetext{
${ }^{65}$ A.g.e., s. IV-36.

${ }^{66}$ A.g.e., s. VII-1.
} 
Türk Stratejik Kültüründe Çözümü Çerçevelemek:

Katmanlı Bir Harekât Tasarımı Önerisi

\section{Sonuç}

Savaşın "değişen" doğası, son dönem yazarlarının da kullanmayı sevdikleri bir kavramdır. Gerçekte bir şey değişmiş midir ya da değişen nedir? Burada bilinçaltında problematize ettiğimiz şey esasen devletler arasındaki konvansiyonel savaş biçiminin dönüşüme uğramasıdır. Diğer bir deyişle devlet, sofistike ve karmaşık çağımızda, Veberci şiddet tekeli olma özelliğini kaybetmektedir. Bu durum Clausewitz'in işaret ettiği "ilkel şiddet" haline hızla doğru evrilmektedir. Hızla değişen koşullar altında, karmaşık harekât probleminin anlaşılması ya da çerçevelenmesi için kullanılan harekât tasarımı ve operatif sanat da süratle değişime uğruyor. Değişim ve aşınmanın hızı, aynı şiddette ve hatta ondan daha hızlı bir biçimde, kötü problemi anlamayı ve karar almayı gerektiriyor.

Atatürk harbi, sürekli mücadele halinde bulunan gözle görülmez kuvvetlerin göze görünür şekil ve görünüş alması olarak tanımlar. ${ }^{67}$ Clausewitz'in teorisine göre de harp, rakibin diğerini kendi iradesine boyun eğmeye zorlamaya çalıştığı bir mücadeledir. ${ }^{68}$ Herhangi bir irade mücadelesinde olduğu gibi, hasma karşı bir avantaj elde etmek, büyük ölçüde ortamı ve meseleyi anlamaya ve tanımlamaya bağlıdır. Meseleyi anlamak için oluşturulan modeller çoğunlukla deneyim ve muhakeme yoluyla geliştirilmiştir. Deneyime dayanan karar verme, pragmatik düşünceyle yakından ilişkilidir. Doğru uygulandığı takdirde pragmatik düşünce, karar alıcılar için firsatlar sunar.

Tarihin ünlü stratejistlerinin ortak özelliği, durumu ve meseleyi herkesten iyi anlama yetenekleridir. Ancak herkes Atatürk, Fatih Sultan Mehmet ya da Yavuz Sultan Selim olamaz. Bir harekât planı oluşturmak için yalnızca kişisel deneyim ve muhakemeyi kullanmak, özellikle tek bir kişi tarafından anlaşılamayan veya çözülemeyen kötü meseleleri çözmeye çalışmak, büyük gayret sarfına neden olur. Günümüz hibrit savaş ortamında bu gayret sarfının daha büyük

\footnotetext{
${ }^{67}$ Atatürk'ün Söylev ve Demeçleri, s. 206.

${ }^{68}$ Clausewitz, a.g.e., s. 20.
} 
Özgür KÖRPE

196

Güvenlik Stratejileri

Cilt: 17

Sayı: 37

kayıplara yol açması kaçınılmazdır. Harekât tasarımı ve operatif sanat, bu boşluğu pragmatik bir yaklaşımla doldurma iddiasındadır.

Harekât tasarımı esasen basitçe harekâta ilişkin bir modeldir. Tasarımın çizdiği çerçeve, ev inşa eden birisine; dört duvara, bir zemine, tavana, kapıya, birkaç pencereye, elektrik prizlerine ve su tesisatına ihtiyacı olduğunu gösterir. Bunlar bir ev inşa etmek için gerekli olabilir ama yeterli değildir. Mesela hatalı bir modelde sıhhi tesisat boruları ve elektrik kabloları duvarların dışından da geçebilir; salona vasistas, banyoya büyük pencere takılması da mümkündür. Binayı doğru bir şekilde inşa edebilecek olan tüm niteliksel yöntemler, operatif sanat olarak adlandırılır. Bina örneğinde bu unsurlar sihhi tesisat, aydınlatma, alan kullanımı, renkler ve dokular gibi düzenlemelerdir.

İşte bu nedenden dolayı çerçeveleme hususunda vazife tahlili, harekât tasarımı ve operatif sanat arasında yakın ve simbiyotik bir ilişki vardır. Bu üç öğenin her birisi ortamı, meseleyi ve çözümü tanımlamayı ve çerçevelemeyi sağlarlar. Vazife tahlili, istenen son durum veya maksadı ortaya koyarak, meseleyi çerçevelemede harekât tasarımına katkı sunar. Operatif sanat ise tasarım ve planlama arasında köprü vazife görür ve bunları birbirine bağlar.

Günümüz meseleleri karmaş1ktan da öte, hibrittir. Meselelerin bu niteliği, sistem yaklaşımının lineer bakış açısından daha farklı, katmanlı bir bakışı gerektirmektedir. Bu makalede harekât tasarımı kavramı, pragmatik bir mantıkla yeniden ele alındı. Halen yaygın olarak uygulanan ağırlık merkezi odaklı zihin haritalaması yaklaşımının eksiklikleri ve harekât tasarımının geliştirilmesi için kullanılabilecek yöntemler gösterildi. Pragmatizm, tasarımın fikrî çerçevesinin simetri merkezi olarak, hibrit meselelerin tanımlanmasında, özellikle de istenen son durumun ortaya koyulmasında oldukça faydalı bir çözüm sunmaktadır. $\mathrm{Bu}$ nedenle de harekât tasarımına yönelik bir pragmatik bakış açısı sunuldu. Bu pragmatik bakış açısı, harekât tasarımına hibrit yaklaşımı önermekte ve katmanlı bir tasarım metodolojisi geliştirmektedir. Pragmatik düşünce, Türk stratejik kültüründe bulunan ve bu nedenle Atatürk'ün karar davranışına da yansıyan gözden kaçırılmaması gereken bir bilişsel yöntemdir. 
Türk Stratejik Kültüründe Çözümü Çerçevelemek:

Katmanlı Bir Harekât Tasarımı Önerisi

Harekât tasarımında kullanılan yürürlükteki zihin haritasına ilave olarak önerilen şablonlar ve tasarım katmanları; ortam çerçeveleme katmanı, mesele çerçeveleme katmanı, harekât yaklaşımı geliştirme katmanı ile dalga etkisi şablonu, maksadın uyumluluğu matrisi, ağırlık merkezi için faktör analizi katmanı ve Vazife-Harekât Tasarımı-Operatif Sanat ilişki şablonudur. Bunlar ihtiyaca göre arttırılıp azaltılabilir; önemli olan tasarımın işlevselliğidir.

Günümüz karmaşık harekât ortamında lineer bir bakış açısına bağımlı kalmamak gerektiği ve tasarım yöntemlerinin çeşitlendirilmesinin planlayıcılarla karar alıcılara bilişsel bir esneklik sağlayabileceği değerlendirilmektedir. Harekâtın icrasında yöntemler birleştirilebiliyorsa, tasarım ve planlamanın da bu süreçlerin gerisinde kalmaması gerekir.

\section{Summary}

The "changing" nature of war is a concept that recent writers also like to use. Has something really changed or what has changed? What we subconsciously problematize here is essentially the transformation of the conventional form of warfare between states. In other words, in our sophisticated and complex age, the state loses its Weberian monopoly on violence. This situation is rapidly evolving into the "primordial violence" pointed out by Clausewitz. Under rapidly changing conditions, the operational design and operative art used to understand or frame the complex operational problem are also rapidly changing. The speed of change and erosion requires understanding the wicked problem and making decisions with the same intensity and even faster.

Atatürk defines the war as the visible shape and appearance of the invisible forces in constant struggle. First of all, warfare is inherently fraught with risks and uncertainties. The main task of the officer and the commander is to manage these risks and reduce uncertainty. Leaving aside all the effects of technological, social or political developments, the main determinant of the change in the means and methods used in war is the "purpose". The purpose is an intuition of the outcome of the war, formed in the mind of the political / military elite at the strategic level and the commander at the operational level. In other words, the purpose is the

\section{7}

Güvenlik Stratejileri

Cilt: 17

Say1: 37 


\section{Özgür KÖRPE}

198

Güvenlik Stratejileri

Cilt: 17

Sayı: 37

ideal of the decision-maker. All planning efforts regarding the war [in this context the operational design efforts] are aimed at achieving this ideal. Although complexity is a phenomenon that can be encountered in all areas of life and at every level of military operation, the possibilities and capabilities that can reduce complexity can only be reached at an operational and strategic level. In other words, tactical commanders have fewer resources than operational and strategic decision makers to reduce complexity.

For this reason, tactical-level commanders implement the decisions of the operational level into practice. However, this situation also imposes the operational level a separate responsibility to facilitate the execution of the tactical level. Because the complex problems are often broad and dynamic, operational design focuses on the determination of the problem, in other words, the analysis results of the task. Operational design logic is based on the premise that if an issue is understood well enough, the solution to the issue will arise automatically. Operational design's focus on determining the issue correctly makes it one of the first analytical activities of MDMP with the mission analysis. It is considered that adding pragmatic thinking as the center of symmetry to conceptual framework of operational design.

In this article a generic operational design was reconsidered with a hybrid logic. Center-of-gravity focused mind-mapping and operational design method currently widely used to investigate problems has been cited. Pragmatism, as the center of symmetry of the intellectual framework of the design, offers a very useful solution in defining wicked hybrid problems, especially in putting forward the final situation. Therefore, a pragmatic perspective on operational design was presented. This pragmatic perspective suggests an approach to operational design and develops a layered design methodology.

Pragmatic thinking is a cognitive method found in the Turkish strategic culture and therefore reflected in Atatürk's decision behavior, which should not be overlooked. In this context, a pragmatic perspective on operational design was presented. This pragmatic perspective proposes a hybrid approach to operational design and develops a layered and creative design methodology. In addition to the current mind map, some 
Türk Stratejik Kültüründe Çözümü Çerçevelemek:

Katmanlı Bir Harekât Tasarımı Önerisi

suggested design layers are Purpose Coherence Matrix, Factor Analysis Layer for COG and Mission-Operational Design-Operational Art Relationship layer.

In today's complex operation environment, it is considered that it is not necessary to be dependent on a linear perspective, and that diversification of design methods can provide cognitive flexibility to planners and decision makers. If the methods can be combined in the execution of the operation, design and planning should not fall behind these processes.

\section{KAYNAKÇA \\ Kitaplar}

Atatürk Kültür, Dil ve Tarih Yüksek Kurumu Atatürk Araştırma Merkezi, Atatürk'ün Söylev ve Demeçleri I-III (Açıklamalı Dizin İle), Ankara 2006.

ATATÜRK, Mustafa Kemal, Anafartalar Muharebeleri'ne Ait Tarihçe, yay.krl. Abdullah Atay, Sertif Demir, Yusuf Serdar Demirtaş, Genelkurmay Askerî Tarih ve Stratejik Etüt Başkanlığı Yayınları, Ankara 2011.

ATATÜRK, Mustafa Kemal, Nutuk, yay. haz. Zeynep Korkmaz. Atatürk Kültür, Dil ve Tarih Yüksek Kurumu Atatürk Araştırma Merkezi Yayınları, Ankara, 2005.

ATATÜRK, Mustafa Kemal, Taktik Meselesinin Çözümüne ve Emirlerin Yazılmasına İlişkin Öğütler, Genelkurmay Basımevi, Ankara 2011.

BROCKMAN, John. Gelecek 50 Yll: 21. Yüzyılın Illk Yarısında Sanat ve Bilim. Çev.: Nurettin Elhüseyni. NTV Yayınları. İstanbul 2008.

CLAUSEWITZ, Carl von, Savaş Üzerine, (Çev. H. Fahri Çelikel), Özne Yayınları, İstanbul 1999.

DAVISON, Ketti, C., Systemic Operational Design (SOD): Gaining and Maintaining the Cognitive Initiative, BiblioScholar, Washington DC, USA 2011.

Department of Defense, FM 3-0 Operations, Washington DC, USA, 2017.

Department of Defense, FM 5-0, Operations Process, Washington, DC, USA, 2010.

Department of Defense, FMI 5-2 Design, Washington DC, USA, 2009.

FRANKS, Tommy R. American Soldier, William Morrow Paperbacks, New York, NY, USA 2005.

HOFFMAN, Frank G. Conflict in the 21st Century: The Rise of Hybrid Wars. Potomac Institute for Policy Studies. Virginia, USA. 2007.

JOHNSTON, Alastair I. Cultural Realism: Strategic Culture and Grand Strategy in Chinese History, Princeton, USA: Princeton University Press, 1998. 


\section{Özgür KÖRPE}

200

Güvenlik Stratejileri

Cilt: 17

Sayı: 37

Joint Warfighting Center, Design in Military Operations, JWFC Publication, Norfolk, Virginia, USA 2011.

KARDEŞ, M. Ertan. Yönsüzleşmiş Savaşlar: Politik Felsefenin Bir Sinır Meselesi Olarak Savaşa Dair. Pinhan Yayıncılık, İstanbul, 2019.

KEM, Jack D., Campaign Planning: Tools of the Trade (Department of Joint and Multinational Operations), U.S. Army Command General Staff College, Kansas, USA 2002.

KIRIK, Hikmet ve Oya Morva, Cumhuriyet ve Pragmatizm: Yazılmamış Kuram, Doruk Yayınc1lık, İstanbul, 2016.

KÖRPE, Özgür. Cesur ve Pragmatik: Atatürk ve Türk Stratejik Kültüründeki İnce Ayar. İlgi Kültür Yayıncılık, İstanbul, 2021.

LONGHURST, Kerry, Germany and the Use of Force: The Evolution of Germany Security Policy 1990-2003 (Issues in German Politics), Manchester University Press, Mancherster, UK, 2005.

MORGAN, Forrest E., Compellence and the Strategic Culture of Imperial Japan: Implications for Coercive Diplomacy in the Twenty-First Century, Praeger Publishers, Westport, CT, USA, 2003.

NAVEH, Shimon. In Pursuit of Military Excellence, Routledge, Cambridge, USA, 1997.

REILLY, Jeffrey M., Operational Design: Distilling Clarity from Complexity for Decisive Action, Air University Press, Alabama, USA, 2021.

STRANGE, Joe, Iron, Richard, Understanding Centers of Gravity and Critical Vulnerabilities, Department of War Studies, Swedish National Defence College, 2005.

TYLER, Brian J., Intelligence and Design: Thinking about Operational Art, Air University Press, Alabama, USA, 2014.

WALDROP, Melanie Mitchell, Complexity: A Guided Tour. Oxford University Press. New York, NY, USA, 2009.

Makaleler

BASRUR, Rajesh M., "Nuclear Weapons and Indian Strategic Culture," Journal of Peace Research, 2001, Vol. 38, 181-198.

FENG, Huiyun. "The Operational Code of Mao Zedong: Defensive or Offensive Realist", Security Studies, c. 14 (4), October-December 2005, 637-662.

KÖRPE, Özgür. "Stratejik Kültür ve Güncel Kuramsal Tartışmalar", Güvenlik Stratejileri Dergisi, Kasım 2016, Y11: 12, Say1: 24, 147-182.

SCHMITT, John F., “A Systemic Concept for Operational Design”, the Marine Corps Combat Development Command, Concepts and Plans Division, Marine Corps Warfighting Lab, August 2006.

WALKER, Stephen G. "The Motivational Foundations of Political Belief Systems", International Studies Quarterly, c. 27. 1983, 179-201.

YAYLA, Yasin. "Türkiye Türkçesinde mana birleşmesi problemi: "Gaye", "Hedef", "Maksat", "Amaç" örneği", Rumelide Dil ve Edebiyat Araştırmaları Dergisi, 2020, (20), 145-156. 
Türk Stratejik Kültüründe Çözümü Çerçevelemek:

Katmanlı Bir Harekât Tasarımı Önerisi

\section{Kitapta Bölümler}

AXELROD, Robert, "Decision for Neoimperialism: The Deliberations of the British Eastern Committee in 1918" in Structure of Decision: Cognitive Maps of Political Elites, Robert Axelrod, (ed.), Princeton University Press, New Jersey, USA, 1976, 77-95.

HODGKINSON, Gerard P. and A. John Maule, "The Individual in the Strategy Process: Insights from Behavioural Decision Research and Cognitive Mapping" in Mapping Strategic Knowledge, Anne S. Huff, Mark Jenkins, (ed.), Sage Publishing, Thousand Oaks, CA, USA, 2002, 196-219.

SNYDER, Jack L. "The Concept of Strategic Culture: Caveat Emptor," in C.G. Jacobsen, (ed.), Strategic Power: USA/USSR, St Martin's Press, New York, NY, USA, 1990, 3-9.

\section{İnternet Kaynakları}

MATTIS, James N., Memorandum for US Joint Forces Command: Vision for a Joint Approach to Operational Design." Norfolk, VA: US Joint Forces Command, 6 October 2009. JFCOM web sitesi, http://www.jfcom.mil/newslink/storyarchive/2009/ aod_2009.pdf, (Erişim Tarihi 30.01.2021).

WARDEN, John A. III, "The Enemy as a System," Airpower Journal, Airpower Journal sitesi www.airpower.maxwell.af.mil/airchronicles/apj/apj95/spr95files /warden.htm, (Erişim Tarihi 28.12.2020). 